\title{
Photoswitchable gating of non-equilibrium enzymatic feedback in chemically communicating polymersome nanoreactors
}

\section{Omar Rifaie-Graham}

Imperial College London https://orcid.org/0000-0003-1403-0537

Jonathan Yeow

Imperial College London

Adrian Najer

Imperial College London

Richard Wang

Imperial College London

Rujie Sun

Imperial College London

Kun Zhou

Imperial College London

Tristan Dell

Imperial College London https://orcid.org/0000-0001-8960-4334

Christopher Adrianus

Impoerial College London

Chalaisorn Thanapongpibul

Imperial College London

Stephen Mann

University of Bristol https://orcid.org/0000-0003-3012-8964

Javier Read de Alaniz

University of California Santa Barbara

Molly Stevens ( $\square$ m.stevens@imperial.ac.uk)

Imperial College London https://orcid.org/0000-0002-7335-266X

\section{Article}

Keywords:

Posted Date: February 11th, 2022

DOI: https://doi.org/10.21203/rs.3.rs-1157089/v1 
License: (c) (i) This work is licensed under a Creative Commons Attribution 4.0 International License. Read Full License

Version of Record: A version of this preprint was published at Nature Chemistry on November 7th, 2022. See the published version at https://doi.org/10.1038/s41557-022-01062-4. 


\section{Abstract}

The circadian rhythm generates out-of-equilibrium metabolite oscillations controlled by feedback loops under light/dark cycles. Here we describe a non-equilibrium nanosystem comprising a binary population of enzyme-containing polymersomes capable of light-gated chemical communication, controllable feedback and coupling to macroscopic oscillations. The populations consist of esterase-containing polymersomes functionalized with photo-responsive Donor-Acceptor Stenhouse Adducts (DASA) and light-insensitive semi-permeable urease-loaded polymersomes. The DASA-polymersome membrane becomes permeable under green light, switching on esterase activity and decreasing the $\mathrm{pH}$, which in turn initiates production of alkali in the urease-containing population. A pH-sensitive pigment that absorbs green light when protonated provides a negative feedback loop for deactivating the DASA-polymersomes. Simultaneously, increased alkali production deprotonates the pigment, re-activating esterase activity by opening the membrane gate. We utilise light-mediated fluctuations of $\mathrm{pH}$ to perform non-equilibrium communication between the nanoreactors and use the feedback loops to induce work as chemomechanical swelling/deswelling oscillations in a crosslinked hydrogel. We envision possible applications in artificial organelles, protocells, and soft robotics.

\section{Introduction}

Most life distinguishing features rely on complex molecular assemblies and biochemical reactions that are out-of-equilibrium. ${ }^{1}$ This is possible in living systems owing to a higher level of continuous kinetic control and energy dissipation that is mediated by complex feedback loops. For instance, a vast number of physiological functions in organisms are regulated by time-regulated enzymatic reactions. One prominent example is the circadian rhythm which uses day and night cycles to regulate the alternation of metabolic activity. In these processes, the oscillation of metabolite concentrations is controlled by chemical hierarchical networks of independent oscillators that communicate and regulate each other to adapt to light intensity. Given that metabolites dissipate at a constant rate, the oscillation of physiological functions requires the accumulation of chemical signals through positive feedback loops and the inhibition of their production through negative feedback loops. This leads to the out-ofequilibrium state commonly referred to as homeostasis. The complex and dynamic interplay of these feedback loops in regulating metabolite levels is one of the fundamental hallmarks of living systems and can serve as inspiration for the synthesis of man-made out-of-equilibrium systems.

Polymersomes are self-assembled block copolymer vesicles that can mimic the compartmentalisation of enzymes by cells and organelles, and can be tailored to be permanently semi-permeable to small molecule substrates or to switch semipermeability states in response to chemical and physical stimuli. ${ }^{2-}$ ${ }^{5}$ Such properties can be harnessed to generate enzyme-loaded polymersome nanoreactors which only perform catalysis when they are in an out-of-equilibrium state in response to stimuli. ${ }^{6-10}$ One method that living systems have evolved to maintain these out-of-equilibrium processes is to control the transport of metabolites through chemically selective channels. In mimicking the activity of such stimuli-responsive 
channels within artificial systems, small molecule photoswitches are especially attractive due to their ability to change geometry, polarity, and absorption profiles both in solution and in the solid-state. ${ }^{11}$ This property allows for external spatial and temporal control over molecular systems by simply applying light in a non-invasive manner. ${ }^{12}$ Examples of these systems are polymersomes functionalised with photoresponsive azobenzene or spiropyran moieties. ${ }^{13-14}$ However, these systems respond only within the UV spectrum, and only revert with a secondary irradiation wavelength or thermally over a timescale of days. ${ }^{15-16}$ In contrast, Donor-Acceptor Stenhouse Adducts (DASAs) thermally revert immediately in the absence of light and can also be tuned to selectively absorb within the visible and near-IR spectrum. ${ }^{17-19}$ DASAs are negative photoswitches that shift equilibrium between two isomers. ${ }^{20-21}$ In the dark, the equilibrium is shifted to a colourful triene-enol whereas, under visible light irradiation, a colourless cyclopentenone isomer that is more polar is formed. These features make DASAs highly attractive for robust implementations into different materials for widespread applications. ${ }^{22-30}$ For example, coupling DASAs to the hydrophobic leaflet of polymersomes allows for an out-of-equilibrium state under light irradiation which allows the permeation of molecules across the now semipermeable membrane, recovering to the initial non-permeable state when light is withdrawn. ${ }^{7}$

Inspired by circadian rhythm processes, we designed feedback loops that work in tandem to facilitate modulation of out-of-equilibrium pH states powered by a DASA-functionalised polymersome nanoreactor containing an esterase enzyme (DASA-esterase) (Figure 1A). DASAs mimic photoreceptor-coupled transmembrane channels in living cells by controlling the permeation of substrates through a semipermeable membrane under light. Thus, DASA-polymersomes are ideally suited to modulate feedback loops externally triggered by light. When DASA-esterase was irradiated with green light, the polymersome membrane became semipermeable to facilitate access of the substrate (ethyl acetate) to the encapsulated enzyme for the generation of acetic acid. The first negative feedback loop within this system was produced by coupling this formation of acid with the pH-sensitive pigment, methyl red (MR), which transitioned to a green light-absorbing species as the $\mathrm{pH}$ was lowered. As acetic acid was catalytically formed under green light, the formation of the protonated pigment competed with the DASAnanoreactor for the absorption of light until the catalysis was interrupted by deactivation of the photoswitching capacity of the DASA. The second level of regulation was introduced by an intrinsically semi-permeable polymersome synthesised by polymerisation-induced self-assembly (PISA) ${ }^{31}$ which encapsulated a urease enzyme (PISA-urease) (Figure 1B). Although inactive under basic conditions, acidic conditions drastically increased urease activity to transform its substrate, urea, into basic ammonia (Extended Data Figure 1 and Supplementary Information 1). ${ }^{32-36}$ This formation of base drives the deprotonation of $\mathrm{MR}\left(\mathrm{MR}^{-}\right)$back to its nongreen light absorbing state (Figure 1C). Therefore, the concentration of the green-absorbing protonated MR $(\mathrm{MRH})$ could be modulated by irradiation or withdrawal of green light. Importantly, the control of MRH concentration was associated to lightcontrolled $\mathrm{pH}$ states. This further allowed the modulation of the swelling ratio of a $\mathrm{pH}$-responsive hydrogel, which was immersed in the same medium as the nanoreactors, by transduction of green light into an out-of-equilibrium mechanochemical signal. 


\section{Results And Discussion}

Synthesis of antagonistic polymersome nanoreactors. Current polymersome nanoreactor systems that mimic intercellular communication incorporating out-of-equilibrium feedback loops require medium manipulation through addition of external chemical fuel. ${ }^{6,10}$ In order to provide a mechanism for more precise feedback loop regulation without requiring addition of external chemical fuel, we designed a system that could be externally manipulated by light. This comprised a nanoreactor which alternated small molecule semipermeability states by a photoswitch and by a constantly semi-permeable nanoreactor which contained a $\mathrm{pH}$-sensitive enzyme. To realise the green light triggered nanoreactor (DASA-esterase), a DASA modified amphiphilic block copolymer was synthesised and self-assembled by the solvent exchange method, whilst simultaneously encapsulating esterase (polymer synthesis and characterisation: Extended Data Scheme 1, Extended Data Figure 2-5, and Supplementary Information 25; particle characterisation: Figure 2A, Extended Data Figure 6A-D, 7A, 8, 9 and Supplementary Information 6). In turn, inherently semi-permeable nanoreactors were synthesised using photoinitiated reversible addition-fragmentation chain transfer (RAFT) polymerisation induced self-assembly (photoPISA) with in situ encapsulation of urease to yield PISA-urease (Figure 3A, Extended Data Scheme 1, Extended Data Figure 6E-H, 7B, 10, Supplementary Information 2 and 7). Dynamic light scattering (DLS) revealed nanoparticles with hydrodynamic diameters $\left(D_{h}\right)$ of $207 \pm 13 \mathrm{~nm}$ in the case of DASA-esterase nanoreactors and $D_{h}=362 \pm 22 \mathrm{~nm}$ ) for PISA-urease nanoreactors. Cryogenic transmission electron microscopy (cryo-TEM) micrographs revealed a hollow vesicle morphology for both nanoreactors with average membrane thicknesses found to be $10 \pm 2 \mathrm{~nm}$ for DASA-esterase nanoreactors and $16 \pm 13 \mathrm{~nm}$ for PISA-urease nanoreactors.

DASA photoswitch driven enzymatic feedback loop. To generate lightgated negative feedback behaviour by DASA-esterase nanoreactors, the formation of a product that could compete for the absorption of light was investigated (Figure 2B). The DASA synthesised in this study was a purple compound that presented an absorbance maximum at $\lambda=550 \mathrm{~nm}$, which absorbed green light at $\lambda=530 \mathrm{~nm}$ causing isomer photoswitching (Figure 2C). MR transitioned from a yellow, deprotonated state $\left(\lambda_{\max }=430 \mathrm{~nm}\right.$ ) to a red, protonated state $\left(\lambda_{\max }=520 \mathrm{~nm}\right.$ ) below $\mathrm{pH}$ 7. Thus, DASA-esterase nanoreactors were dispersed in solutions containing ethyl acetate and $\mathrm{MR}^{-}$. To study the light mediated feedback behaviour of these nanoreactors, the dispersions were continuously irradiated with light $(\lambda=530 \mathrm{~nm})$ intensities of 1.49 $\mathrm{mW} \cdot \mathrm{cm}^{-2}$ and $0.76 \mathrm{~mW} \cdot \mathrm{cm}^{-2}$, alongside a dark control with periodic absorbance measurements at $\lambda=$ $530 \mathrm{~nm}$ as a measure of MRH photomask accumulation. Under green light irradiation, a gradual increase of absorbance was observed due to the enzymatic synthesis of acetic acid from ethyl acetate and subsequent formation of MRH (Figure 2D and Extended Data Figure 11). Importantly, in the absence of light, this did not occur owing to the polymersome membrane preventing access of substrate (ethyl acetate) to the enzyme, thus confirming the light gating nature of the DASA nanoreactors between ON and OFF states. Under continuous irradiation, this eventually led to plateaued absorbance indicating that the biocatalysis had reached equilibrium. Moreover, the increased absorbance throughout the process correlated to the intensity of light irradiation. To understand this phenomenon, we followed the changes 
in absorbance of the DASA polymer in both organic solution and concentrated aqueous polymersome dispersions after alternation of green light irradiation and darkness cycles (Figure 2E and Extended Data Figure 12). We observed that the rate of isomerisation of the purple-coloured DASA to the colourless, and more polar cyclopentenone isomer, was faster with higher irradiation intensities. Higher light intensities led to greater changes in permeability, which subsequently increased biocatalytic formation of acetic acid over time. In addition, the plateau formation occurred at absorbance values that were proportional to the light irradiation intensity. We hypothesised that the accumulation of MRH masked the penetration of green light, limiting further absorption of light by DASA-esterase decreasing the permeability of the membrane to the substrate (ethyl acetate) by back isomerisation of the DASA moieties to the less polar triene-enol isomer. Hence, subsequent/further formation of MRH was inhibited. Indeed, higher light intensities penetrated more into the reaction volume and required more $\mathrm{MRH}$ photomask formation to quench the gated enzymatic activity of the nanoreactors. To further confirm this hypothesis, we spiked a reaction which had already reached a stationary plateau phase with free esterase, which resulted in a drastic increase in absorbance, demonstrating that this feedback behaviour was not due to self-inhibited enzyme activity at a given pH (Figure 2F, Extended Data Figure 13, and Supplementary Information 8). This validated the light-driven negative feedback nature of the DASA nanoreactor system, whereby the product formation simultaneously limited its own subsequent production. Importantly, the esterase remained active and the photomasking effect exercised by MRH only interrupted the light-mediated catalysis by DASA-esterase, demonstrating a light-gated negative feedback loop.

\section{Negative feedback automodulation of pH-sensitive PISA-urease nanoreactors. To demonstrate}

modulation of out-of-equilibrium $\mathrm{pH}$ states, a series of experiments was performed to probe the capacity of PISA-urease to produce $\mathrm{MR}^{-}$(Figure 3B). The nanoreactors were immersed in an aqueous solution of acetic acid, $\mathrm{MR}$, and urea (starting $\mathrm{pH}=6.7$ ) and the accumulation of $\mathrm{MR}^{-}$was monitored by kinetic UVVis spectroscopy (Figure $3 \mathrm{C}$ and Supplementary Information 9). An abrupt decay in absorbance was observed indicating that urea passively permeated across the membrane of PISA-urease to generate ammonia leading to $\mathrm{MR}^{-}$formation over time. This process eventually led to a plateau in absorbance, which corresponded to the well-known inactivation of urease enzymes in basic conditions. ${ }^{37}$ Importantly, further addition of free urease did not result in absorbance reduction (Figure 3C). To exclude that this phenomenon was due to the total consumption of substrate fuel (urea), the dispersions were acidified with additional acetic acid $(\mathrm{pH}=6.8)$ to generate $\mathrm{MRH}$ again (Figure $3 \mathrm{C}$ ). Upon acidification, the absorbance decayed over time in a similar fashion to the first cycle, until a plateau was again reached at a similar absorbance. In addition, the $\mathrm{pH}$ was calculated using a pH calibration curve for MR (Figure 3D and Supplementary Information 9 and 10) confirming the inhibition of PISA-urease nanoreactors at $\mathrm{pH}$ 8.6. This system, therefore, represented a second $\mathrm{pH}$ mediated negative feedback loop whereby the basicity increased (as evidenced by the production of $\mathrm{MR}^{-}$) to deactivate further catalysis by PISA-urease nanoreactors. Given that the activity of PISA-urease decreased the concentration of the accumulated MRH photomask, these results highlighted the potential to reinitiate the catalytic activity of DASAesterase when mixing both nanoreactor populations. 
Light mediated feedback loop communication between polymersome nanoreactors. In many organisms, circadian rhythm-regulated cell types perform antagonistic enzymatic reactions that control the production rate of metabolites. We sought to mimic aspects of this feature of biological systems with our antagonistic self-regulating nanoreactors to generate controlled fluctuations of $\mathrm{pH}$ by light irradiation intensity or alternation of light irradiation and darkness cycles (Figure 4A).

To generate outofequilibrium $\mathrm{pH}$ modulation by light, both DASA-esterase and PISA-urease nanoreactors were immersed in an unbuffered aqueous solution containing urea, ethyl acetate, and $\mathrm{MR}(\mathrm{pH}=7.8)$. The dispersions were continuously irradiated with green light at intensities of $1.49 \mathrm{~mW} \cdot \mathrm{cm}^{-2}$ and 0.76 $\mathrm{mW} \cdot \mathrm{cm}^{2}$ alongside a dark control, and the $\mathrm{pH}$ change over time was measured (Figure 4B, Extended Data Figure 14, and Supplementary Information 10 and 11). In the absence of light, the pH increased and remained stable at $\mathrm{pH}=8.4$ over $4 \mathrm{~h}$. This was expected, as DASA-esterase nanoreactors were not semipermeable to the substrate (ethyl acetate) to produce acid, and PISA-urease nanoreactors that were initially active, eventually inactivated at higher $\mathrm{pH}$ values in agreement with Figures $3 \mathrm{C}$ and 3D. In contrast, when the system was irradiated with green light, a gradual decrease in $\mathrm{pH}$ was observed indicating the formation of MRH due to acetic acid production from DASA-esterase. Importantly, higher concentrations of DASA-esterase were required to observe $\mathrm{pH}$ changes compared to experiments in the absence of PISA-urease (Figure 4C, Figure 2, and Extended Data Figure 15). In addition, lower PISA-urease : DASA-esterase (PU:DE) number ratios generated lower stationary plateau $\mathrm{pH}$ values presumably because the ongoing activation of PISA-urease occurred at $\mathrm{pH}$ values closer to the optimum required to compensate for the increased level of esterase activity. In accordance with the previous experiments involving DASA-esterase only, the plateaued $\mathrm{pH}$ values were proportional to the irradiation intensities (Figure 4B). When the light irradiation was withdrawn the out-of-equilibrium $\mathrm{pH}$ values gradually reverted to basic conditions, with higher alkalinisation kinetics at lower $\mathrm{pH}$ values owing to higher enzymatic activity of PISA-urease (Figure 4B and 4C, and Extended Data Figures 14 and 15). Importantly, the individual behaviours of both DASA-esterase and PISA-urease were preserved highlighting the ability of our system to precisely control $\mathrm{pH}$ in out-of-equilibrium systems using visible light.

In contrast to experiments where the production of acetic acid was not down-regulated by the presence of PISA-urease (Figure 2D), the dispersions containing both DASA-esterase and PISAurease had the ability to drive back to alkaline $\mathrm{pH}$ autonomously in absence of light irradiation. Thus, we sought to showcase the modulation of chemical species formation by alternating between green light and dark cycles, allowing the catalytic activity of DASA-esterase to be switched ON and OFF (Extended Data Figure 16 and Supplementary Information 12). DASA-esterase and PISA-urease were dispersed in solutions of MR, ethyl acetate, and urea $(\mathrm{pH}=7.8)$ followed by alternating green light irradiation at $4.31 \mathrm{~mW} \cdot \mathrm{cm}^{-2}$ for periods of $10 \mathrm{~min}$ and periods of $15 \mathrm{~min}$ in darkness whilst monitoring the $\mathrm{pH}$ fluctuations by UV-Vis spectroscopy (Figure 4D, Extended Data Figure 17, and Supplementary Information 13). After the first irradiation cycle, DASA-esterase transformed the substrate (ethyl acetate) into acetic acid producing a decrease to $\mathrm{pH}=$ 6.7. Throughout the first darkness cycle, the $\mathrm{pH}$ gradually increased to $\mathrm{pH}=7.0$ by the acid-mediated activation of PISA-urease, transforming urea into ammonia. Over the following 7 cycles, the system 
displayed alternating shifts of light induced acid formation and basicity in dark conditions. This can be attributed to reversible switching of the photoresponsive DASA membrane gate. Interestingly, the pH range became gradually more basic over the course of each irradiation and darkness cycle. Beyond fuel consumption, the loss in light-induced esterase activity may be explained by the loss of enzymatic activity due to various factors including the build-up of buffer salts in the confined reaction volume. This hypothesis was confirmed in further experiments (Figure 5E).

Overall, the communication between DASA-esterase and PISA-urease nanoreactors was governed by the two independent negative feedback loops, as described above, and by two positive feedback loops. Light activated the production of acetic acid and MRH, which activated PISA-urease. The production of ammonia by PISA-urease generated MR, allowing light to stimulate the catalysis of more acetic acid and $\mathrm{MRH}$. This process constituted a first positive feedback loop. In turn, the production of ammonia, by PISAurease, produced $\mathrm{MR}^{-}$, which allowed light to stimulate DASA-esterase and produce more acetic acid and $\mathrm{MRH}$. The shift in $\mathrm{pH}$ further activated the production of ammonia by PISA-urease, thereby constituting a second positive feedback loop (Figure 1C). Conceptually, this lightpowered process mimics aspects of the complex circadian rhythm feedback loops observed in living organisms.

\section{Out-of-equilibrium chemomechanical coupling of polymersome nanoreactors in swellable hydrogels. In}

multicellular organisms, the modulation of metabolite concentrations can reversibly control the physical state of tissues and organs. Inspired by such processes, we investigated how the light-mediated modulation of $\mathrm{pH}$ states by DASAesterase and PISA-urease nanoreactors could be coupled to the swelling of a hydrogel as a rudimentary representation how chemomechanical work could be generated by an out-of-equilibrium nanoreactor network. For this purpose, we synthesised hydrogels of chemically crosslinked poly( $N$-isopropylacrylamide)-co-poly(2-(dimethylamino)ethyl methacrylate)-co-poly(Nile blue acrylamide) (PNIPAAm-co-PDMAEMA-co-PNBA) containing a tertiary amine. These become protonated at acidic $\mathrm{pH}(\mathrm{pKa} \sim 7.5)^{38}$ and swell (Figure $5 \mathrm{~A}$ ). Nile blue was incorporated to facilitate image contrast.

The circular gels $(\mathrm{d}=2 \mathrm{~mm})$ were immersed in dispersions containing the two nanoreactor populations at different number ratios as well as MR, ethyl acetate, and urea. After equilibration for $1 \mathrm{~h}$, the samples were irradiated with green light $\left(1.49 \mathrm{~mW} \cdot \mathrm{cm}^{-2}\right)$ and the hydrogel swelling ratio was monitored over $4 \mathrm{~h}$ using a dermatoscope (Figure 5B, and Supplementary Information 14). Upon light irradiation, DASAesterase nanoreactors became semi-permeable to the substrate (ethyl acetate) allowing the catalytic formation of acetic acid which simultaneously protonated the reporter to $\mathrm{MRH}$ and the $\mathrm{pH}$-responsive hydrogel inducing its swelling. Eventually, the swelling process reached a plateau indicating equilibrium of the hydrogels with the bulk solution $\mathrm{pH}$. Importantly, the out-of-equilibrium swelling states were proportional to the PU:DE number ratio. In accordance with spectroscopic measurements of pH (Figure 4C), lower PU:DE ratios generated lower stationary $\mathrm{pH}$ values that translated into higher protonation and swelling states of the hydrogels.

To test the role of MRH formation as a modulator of hydrogel swelling, we immersed the hydrogels in dispersions containing fixed concentrations of the two nanoreactor populations and irradiated them with 
green light at $1.49 \mathrm{~mW} \cdot \mathrm{cm}^{-2}$ in the presence and absence of $\mathrm{MR}^{-}$alongside a control in darkness (Figure $5 \mathrm{C}$ ). Whilst hydrogel swelling was not observed in darkness, higher swelling rates were observed in samples that did not contain MR. The results indicate that the formation of acid and subsequent protonation of the hydrogel was limited by the negative feedback generated by accumulation of the photomask MRH. In addition, similar behaviour was observed in experiments where DASA-esterase was present and PISA-urease was absent, which additionally generated higher swelling states (Figure 5C). To demonstrate that the hydrogel swelling was an out-of-equilibrium state, the samples were investigated after withdrawal of green light. After removing the light source, the enzymatic production of acetic acid was interrupted and PISA-urease nanoreactors dominated the modulation of $\mathrm{pH}$ by accumulation of basic ammonia. This caused progressive deprotonation of the hydrogel tertiary amines leading to gradual de-swelling. The swelling could be reinitiated by addition of substrate fuel (ethyl acetate and urea) and further irradiation with green light for another $4 \mathrm{~h}$ demonstrating the reversible nature of this ternary system. Overall, the changes in swelling state of the hydrogels were consistent with the changes in pH observed in spectroscopic measurements (Figure 4). These results confirm that the chemical species generated during the out-of-equilibrium communication of the antagonistic nanoreactors can be employed for chemomechanical work, thereby modulating the physical properties of an auxiliary hydrogel akin to solid tissue matrices.

\section{Conclusion And Future Perspective}

Bioinspired out-of-equilibrium materials that require constant energy to maintain activated states of organisation or chemical composition provide a step to the next generation of molecular materials with adaptive, autonomous, and intelligent behaviour. ${ }^{39-50}$ Cells require constant energy supply to remain in an out-of-equilibrium state and perform functions that dictate their survival. In this study, we showcase how a ternary system of polymersome nanoreactors and a hydrogel could be employed to mimic complex biological communication processes and self-regulate their behaviour through positive and negative feedback loops. These nanoreactors, which are in a dormant equilibrium state in dark alkaline conditions, shift to an out-of-equilibrium state when irradiated with light. Importantly, the system is composed of three delayed chemical modulators. First, the permeability of DASA-esterase to its substrate fuel is modulated by the presence of light. Second, the $\mathrm{pH}$ of the bulk solution evolves in a delayed manner by the accumulation of acid and alkali by DASA-esterase and PISA-urease, respectively. Third, a delayed swelling and deswelling of the hydrogel occurs in response to the modulation of $\mathrm{pH}$ in the bulk solution. With further optimisation, such systems could be adapted for novel and diverse applications including artificial organelles, protocells or soft robotic prototissues.

To date, most reports employing enzymes in out-of-equilibrium conditions require a constant supply of chemical fuel to maintain their output chemical signals, thus hindering their application in closed materials. ${ }^{1}$ In contrast, the work described herein showcased a system which can be shifted ON and OFF by an external macroscopic stimulus, until the chemical fuel is consumed. Another important achievement of this work is successfully deciphering a method to modulate the medium pH by light- 
controlled enzymes. Such approaches can be employed as a powerful tool to control a wide spectrum of catalysts as, in many cases, their turnover can be modulated by approximation to their optimal $\mathrm{pH}$. Towards the goal replicating of living biological materials, understanding the underlying concepts behind the molecular mechanisms which drive biological functions can provide key insights into the fabrication of novel outof-equilibrium systems and materials. In this regard, polymersome nanoreactors mimic the compartmentalising nature of biological membranes, and represent a robust platform for the creation of complex functional materials with life-like properties. The future outlook for this work will expand on employing light-responsive nanoreactors with a broader range of enzymes to animate materials capable of autonomous motion, and self-organisation, self-actuation and adaptive behaviour.

\section{Declarations}

\section{Acknowledgements}

O.R-G. kindly thanks the support given by the Swiss National Science Foundation (SNSF) through an Early Postdoc.Mobility Fellowship (P2FRP2_181432) and the European Union's Horizon 2020 research and innovation programme under the Marie Sklodowska-Curie grant agreement (893158). J.Y. acknowledges funding from the European Union's Horizon 2020 research and innovation programme under the Marie Skłodowska-Curie grant agreement (839137). A.N. was supported from his previous SNSF Early Postdoc.Mobility Fellowship (P2BSP2_168751) and current Sir Henry Wellcome Postdoctoral Fellowship (209121_Z_17_Z) from the Wellcome Trust. R.W. acknowledges funding from The Rosetrees Trust under the Young Enterprise Fellowship agreement (A2741/M873). T.D. received funding under the EPSRC Doctoral Training Partnership (EP/R513052/1). C.A. acknowledges funding from Agency for Science, Technology and Research Singapore through a National Science Scholarship. C.T. acknowledges support from a Royal Thai Government scholarship. S.M. acknowledges financial support from the European Commission (8082 H2020 PCELLS 740235). M.M.S. acknowledges support from the Royal Academy of Engineering under the Chairs in Emerging Technologies scheme (CIET2021\94).

The authors would like to thank Dr Pasi Purhonen for cryo-TEM measurements node at the Resource Center for Coordination of Electron Microscopy (RSEM) at KTH Royal Institute of Technology (Sweden), Dr Yingqi Xu for aid with NMR spectrometers at the CFNMR Centre at Imperial College London, and Dr Akemi Nogiwa Valdez for extensive manuscript and data management support. We acknowledge access to facilities at the Harvey Flower Electron Microscopy Suite (Department of Materials, Imperial College London) and the Light Microscopy Facilities at the Francis Crick Institute (London, UK).

\section{Conflict of Interest}

The authors declare no competing interest.

\section{Author Contributions}


O. R.-G. and J.Y. conceived the project. O.R.-G. synthesised DASA-esterase nanoreactors, performed nanoreactor spectroscopic measurements, bright field imaging. J.Y. synthesised PISA-urease nanoreactors. A.N. performed FCS measurements. R.W., K.Z., and R.S. contributed to the fabrication of gels. C.A. and C.T. assisted with the characterisation of nanoreactors. T.D. characterised DASA photoswitching. S.M. assisted with expertise on nanoreactor communication and characterisation of the hydrogel experiments. J.R.A assisted with expertise on DASAs and light-mediated modulation of solidstate hydrogels. M.M.S. co-supervised the project. All authors contributed to project discussions. O.R.-G. co-supervised the project and wrote the text with feedback from all authors.

\section{References}

1. Merindol, R.; Walther, A., Materials learning from life: concepts for active, adaptive and autonomous molecular systems. Chem. Soc. Rev. 2017, 46 (18), 5588-5619.

2. Marguet, M.; Bonduelle, C.; Lecommandoux, S., Multicompartmentalized polymeric systems: towards biomimetic cellular structure and function. Chem. Soc. Rev. 2013, 42 (2), 512-529.

3. Küchler, A.; Yoshimoto, M.; Luginbühl, S.; Mavelli, F.; Walde, P., Enzymatic reactions in confined environments. Nature Nanotecnol. 2016, 11 (5), 409.

4. Palivan, C. G.; Goers, R.; Najer, A.; Zhang, X.; Car, A.; Meier, W., Bioinspired polymer vesicles and membranes for biological and medical applications. Chem. Soc. Rev. 2016, 45 (2), 377-411.

5. Discher, D. E.; Eisenberg, A., Polymer vesicles. Science 2002, 297 (5583), 967-973.

6. Che, H.; Cao, S.; van Hest, J. C., Feedback-induced temporal control of "breathing" polymersomes to create self-adaptive nanoreactors. J. Am. Chem. Soc. 2018, 140 (16), 5356-5359.

7. Rifaie-Graham, O.; Ulrich, S.; Galensowske, N. F.; Balog, S.; Chami, M.; Rentsch, D.; Hemmer, J. R.; Read de Alaniz, J.; Boesel, L. F.; Bruns, N., Wavelength-Selective Light-Responsive DASA-Functionalized Polymersome Nanoreactors. J. Am. Chem. Soc. 2018, 140, 8027-8036.

8. Rifaie-Graham, O.; Galensowske, N. F. B.; Dean, C.; Pollard, J.; Balog, S.; Gouveia, M. G.; Chami, M.; Vian, A.; Amstad, E.; Lattuada, M.; Bruns, N., Shear Stress-Responsive Polymersome Nanoreactors Inspired by the Marine Bioluminescence of Dinoflagellates. Angew. Chem., Int. Ed. 2021, 60 (2), 904-909.

9. $\quad$ Moreno, S.; Sharan, P.; Engelke, J.; Gumz, H.; Boye, S.; Oertel, U.; Wang, P.; Banerjee, S.; Klajn, R.; Voit, B.; Lederer, A.; Appelhans, D., Light-Driven Proton Transfer for Cyclic and Temporal Switching of Enzymatic Nanoreactors. Small 2020, 16 (37), 2002135.

10. Wang, X.; Moreno, S.; Boye, S.; Wen, P.; Zhang, K.; Formanek, P.; Lederer, A.; Voit, B.; Appelhans, D., Feedback-Induced and Oscillating pH Regulation of a Binary Enzyme-Polymersomes System. Chem. Mater. 2021. 
11. Wang, L.; Li, Q., Photochromism into nanosystems: towards lighting up the future nanoworld. Chem. Soc. Rev. 2018, (47), 1044-1097.

12. Jochum, F. D.; Théato, P., Temperature- and light-responsive smart polymer materials. Chem. Soc. Rev. 2013, 42 (17), 7468-7483.

13. Molla, M. R.; Rangadurai, P.; Antony, L.; Swaminathan, S.; de Pablo, J. J.; Thayumanavan, S., Dynamic actuation of glassy polymersomes through isomerization of a single azobenzene unit at the block copolymer interface. Nat. Chem. 2018, 10 (6), 659-666.

14. Wang, X.; Hu, J.; Liu, G.; Tian, J.; Wang, H.; Gong, M.; Liu, S., Reversibly switching bilayer permeability and release modules of photochromic polymersomes stabilized by cooperative noncovalent interactions. J. Am. Chem. Soc. 2015, 137 (48), 15262-15275.

15. Jochum, F. D.; Theato, P., Temperature and light sensitive copolymers containing azobenzene moieties prepared via a polymer analogous reaction. Polymer 2009, 50 (14), 3079-3085.

16. Flannery Jr, J. B., Photo-and thermochromic transients from substituted 1', 3', 3'trimethylindolinobenzospiropyrans. J. Am. Chem. Soc. 1968, 90 (21), 5660-5671.

17. Hemmer, J. R.; Poelma, S. O.; Treat, N.; Page, Z. A.; Dolinski, N. D.; Diaz, Y. J.; Tomlinson, W.; Clark, K. D.; Hooper, J. P.; Hawker, C., Tunable visible and near infrared photoswitches. J. Am. Chem. Soc. 2016, 138 (42), 13960-13966.

18. Hemmer, J. R.; Page, Z. A.; Clark, K. D.; Stricker, F.; Dolinski, N. D.; Hawker, C. J.; Read de Alaniz, J., Controlling Dark Equilibria and Enhancing Donor-Acceptor Stenhouse Adduct Photoswitching Properties through Carbon Acid Design. J. Am. Chem. Soc. 2018, 140 (33), 10425-10429.

19. Helmy, S.; Leibfarth, F. A.; Oh, S.; Poelma, J. E.; Hawker, C. J.; Read de Alaniz, J., Photoswitching using visible light: a new class of organic photochromic molecules. J. Am. Chem. Soc. 2014, 136 (23), 8169-8172.

20. Mallo, N.; Brown, P. T.; Iranmanesh, H.; MacDonald, T. S.; Teusner, M. J.; Harper, J. B.; Ball, G. E.; Beves, J. E., Photochromic switching behaviour of donor-acceptor Stenhouse adducts in organic solvents. Chem. Commun. 2016, 52 (93), 13576-13579.

21. Lerch, M. M.; Wezenberg, S. J.; Szymanski, W.; Feringa, B. L., Unraveling the Photoswitching Mechanism in Donor-Acceptor Stenhouse Adducts. J. Am. Chem. Soc. 2016, 138 (20), 6344-6347.

22. Diaz, Y. J.; Page, Z. A.; Knight, A. S.; Treat, N. J.; Hemmer, J. R.; Hawker, C. J.; Read de Alaniz, J., A Versatile and Highly Selective Colorimetric Sensor for the Detection of Amines. Chem. Eur. J. 2017, 23 (15), 3562-3566. 
23. Dolinski, N. D.; Page, Z. A.; Eisenreich, F.; Niu, J.; Hecht, S.; Read de Alaniz, J.; Hawker, C. J., A Versatile Approach for In Situ Monitoring of Photoswitches and Photopolymerizations.

ChemPhotoChem 2017, 1 (4), 125-131.

24. Jia, S.; Du, J. D.; Hawley, A.; Fong, W.-K.; Graham, B.; Boyd, B. J., Investigation of Donor-Acceptor Stenhouse Adducts as New Visible Wavelength-Responsive Switching Elements for Lipid-Based Liquid Crystalline Systems. Langmuir 2017, 33 (9), 2215-2221.

25. Ulrich, S.; Hemmer, J. R.; Page, Z. A.; Dolinski, N. D.; Rifaie-Graham, O.; Bruns, N.; Hawker, C. J.; Boesel, L. F.; Read de Alaniz, J., Visible light-responsive DASA-polymer conjugates. ACS Macro Lett. 2017, $6(7), 738-742$.

26. Yap, J. E.; Zhang, L.; Lovegrove, J. T.; Beves, J. E.; Stenzel, M. H., Visible Light-Responsive Drug Delivery Nanoparticle via Donor-Acceptor Stenhouse Adducts (DASA). Macromol. Rapid Commun. 2020, 2000236.

27. Senthilkumar, T.; Zhou, L.; Gu, Q.; Liu, L.; Lv, F.; Wang, S., Conjugated Polymer Nanoparticles with Appended Photo-Responsive Units for Controlled Drug Delivery, Release, and Imaging. Angew. Chem. Int. Ed. 2018, 57 (40), 13114-13119.

28. Ulrich, S.; Wang, X.; Rottmar, M.; Rossi, R. M.; Nelson, B. J.; Bruns, N.; Müller, R.; Maniura-Weber, K.; Qin, X. H.; Boesel, L. F., Nano-3D-Printed Photochromic Micro-Objects. Small 2021, 2101337.

29. Lee, J.; Sroda, M. M.; Kwon, Y.; El-Arid, S.; Seshadri, S.; Gockowski, L. F.; Hawkes, E. W.; Valentine, M. T.; Read de Alaniz, J., Tunable Photothermal Actuation Enabled by Photoswitching of Donor-Acceptor Stenhouse Adducts. ACS Appl. Mater. Interfaces 2020, 12 (48), 54075-54082.

30. Chen, Q.; Diaz, Y. J.; Hawker, M. C.; Martinez, M. R.; Page, Z. A.; Xiao-An Zhang, S.; Hawker, C. J.; Read de Alaniz, J., Stable Activated Furan and Donor-Acceptor Stenhouse Adduct Polymer Conjugates as Chemical and Thermal Sensors. Macromolecules 2019, 52 (11), 4370-4375.

31. Blackman, L. D.; Varlas, S.; Arno, M. C.; Fayter, A.; Gibson, M. I.; O’Reilly, R. K., Permeable proteinloaded polymersome cascade nanoreactors by polymerization-induced self-assembly. ACS macro letters 2017, 6 (11), 1263-1267.

32. Hu, G.; Pojman, J. A.; Scott, S. K.; Wrobel, M. M.; Taylor, A. F., Base-catalyzed feedback in the ureaurease reaction. J. Phys. Chem. B 2010, 114 (44), 14059-14063.

33. Heuser, T.; Merindol, R.; Loescher, S.; Klaus, A.; Walther, A., Photonic devices out of equilibrium: transient memory, signal propagation, and sensing. Adv. Mater. 2017, 29 (17), 1606842.

34. Jee, E.; Bánsági Jr, T.; Taylor, A. F.; Pojman, J. A., Temporal control of gelation and polymerization fronts driven by an autocatalytic enzyme reaction. Angew. Chem. Int. Ed. 2016, 55 (6), 2127-2131. 
35. Che, H.; Buddingh', B. C.; van Hest, J. C., Self-Regulated and Temporal Control of a "Breathing" Microgel Mediated by Enzymatic Reaction. Angew. Chem. Int. Ed. 2017, 56 (41), 12581-12585.

36. Gao, N.; Li, M.; Tian, L.; Patil, A. J.; Kumar, B. P.; Mann, S., Chemical-mediated translocation in protocell-based microactuators. Nat. Chem. 2021, 1-12.

37. Wrobel, M. M.; Bánsági Jr, T.; Scott, S. K.; Taylor, A. F.; Bounds, C. O.; Carranza, A.; Pojman, J. A., pH wave-front propagation in the urea-urease reaction. Biophys. J. 2012, 103 (3), 610-615.

38. Li, Y.; Ju, D., The application, neurotoxicity, and related mechanism of cationic polymers. In Neurotoxicity of nanomaterials and nanomedicine, Elsevier: 2017; pp 285-329.

39. Grzybowski, B. A.; Whitesides, G. M., Dynamic aggregation of chiral spinners. Science 2002, 296 (5568), 718-721.

40. Kundu, P. K.; Samanta, D.; Leizrowice, R.; Margulis, B.; Zhao, H.; Börner, M.; Udayabhaskararao, T.; Manna, D.; Klajn, R., Light-controlled self-assembly of non-photoresponsive nanoparticles. Nat. Chem. 2015, 7(8), 646-652.

41. lamsaard, S.; Aßhoff, S. J.; Matt, B.; Kudernac, T.; Cornelissen, J. J.; Fletcher, S. P.; Katsonis, N., Conversion of light into macroscopic helical motion. Nat. Chem. 2014, 6 (3), 229-235.

42. Zhao, H.; Sen, S.; Udayabhaskararao, T.; Sawczyk, M.; Kučanda, K.; Manna, D.; Kundu, P. K.; Lee, J.W.; Král, P.; Klajn, R., Reversible trapping and reaction acceleration within dynamically self-assembling nanoflasks. Nat. Nanotechnol. 2016, 11 (1), 82-88.

43. Leira-Iglesias, J.; Tassoni, A.; Adachi, T.; Stich, M.; Hermans, T. M., Oscillations, travelling fronts and patterns in a supramolecular system. Nat. Nanotechnol. 2018, 13 (11), 1021-1027.

44. Monreal Santiago, G.; Liu, K.; Browne, W. R.; Otto, S., Emergence of light-driven protometabolism on recruitment of a photocatalytic cofactor by a self-replicator. Nat. Chem. 2020, 12 (7), 603-607.

45. Semenov, S. N.; Wong, A. S. Y.; van der Made, R. M.; Postma, S. G. J.; Groen, J.; van Roekel, H. W. H.; de Greef, T. F. A.; Huck, W. T. S., Rational design of functional and tunable oscillating enzymatic networks. Nat. Chem. 2015, 7 (2), 160-165.

46. van der Helm, M. P.; de Beun, T.; Eelkema, R., On the use of catalysis to bias reaction pathways in out-of-equilibrium systems. Chem. Sci. 2021, 12 (12), 4484-4493.

47. Boekhoven, J.; Hendriksen, W. E.; Koper, G. J.; Eelkema, R.; van Esch, J. H., Transient assembly of active materials fueled by a chemical reaction. Science 2015, 349 (6252), 1075-1079.

48. Maiti, S.; Fortunati, I.; Ferrante, C.; Scrimin, P.; Prins, L. J., Dissipative self-assembly of vesicular nanoreactors. Nat. Chem. 2016, 8 (7), 725-731. 
49. Rodríguez-Arco, L.; Li, M.; Mann, S., Phagocytosis-inspired behaviour in synthetic protocell communities of compartmentalized colloidal objects. Nat. Mater. 2017, 16 (8), 857-863.

50. Pearce, S.; Perez-Mercader, J., Chemoadaptive Polymeric Assemblies by Integrated Chemical Feedback in Self-Assembled Synthetic Protocells. ACS Cent. Sci. 2021, 7 (9), 1543-1550.

51. Peter Kapusta, P. G., Absolute Diffusion Coefficients: Compilation of Reference Data for FCS Calibration. 2010, 0-1.

52. Müller, P.; Schwille, P.; Weidemann, T., PyCorrFit-generic data evaluation for fluorescence correlation spectroscopy. Bioinformatics 2014, 30 (17), 2532-2533.

53. Eberhardt, M.; Mruk, R.; Zentel, R.; Théato, P., Synthesis of pentafluorophenyl (meth) acrylate polymers: New precursor polymers for the synthesis of multifunctional materials. Eur. Polym. J. 2005, 41 (7), 1569-1575.

54. Perrier, S.; Takolpuckdee, P.; Mars, C. A., Reversible addition- fragmentation chain transfer polymerization: end group modification for functionalized polymers and chain transfer agent recovery. Macromolecules 2005, 38 (6), 2033-2036.

55. Yin, H.; Jin, M.; Chen, W.; Chen, C.; Zheng, L.; Wei, P.; Han, S., Solvent-free copper-catalyzed Narylation of amino alcohols and diamines with aryl halides. Tetrahedron Lett. 2012, 53 (10), 1265-1270.

56. Helmy, S.; Oh, S.; Leibfarth, F. A.; Hawker, C. J.; Read de Alaniz, J., Design and Synthesis of Donor-Acceptor Stenhouse Adducts: A Visible Light Photoswitch Derived from Furfural. J. Org. Chem 2014, 79 (23), 11316-11329.

\section{Methods}

\section{Materials and equipment}

Poly(ethylene glycol) 4-cyano-4-(phenylcarbonothioylthio)pentanoate $\left(\mathrm{M}_{\mathrm{n}} \sim 2000 \mathrm{~g} \mathrm{~mol}^{-1}\right.$, determined by supplier), 2,6-lutidine (98\%), pentafluorophenol ( $\geq 99 \%)$, acryloyl chloride ( $\geq 97 \%$, contains $\sim 400 \mathrm{ppm}$ phenothiazine as stabilizer), butyl acrylate ( $\geq 99 \%$, contains $10-60 \mathrm{ppm}$ monomethyl ether hydroquinone as inhibitor), 1,4-dioxane (99.8\%), methanol (99.8\%), ethyl acetate (>99.5\%) ( Sudan Blue II (98\%), 2,2dimethyl-1,3-dioxane-4,6-dione (98\%), furfural (99\%), p-iodoanisol (98\%), 1,3-diaminopropane ( $\geq 99 \%)$, copper (I) bromide ( $\geq 99.5 \%)$, triethylamine $(\geq 99.5 \%)$, ammonium sulphate $(\geq 99 \%)$, sodium bicarbonate (>99.5\%), esterase from porcine liver (lyophilized, powder, slightly beige, $\geq 50 \mathrm{U} \mathrm{mg}^{-1}$ ), urease from Canavalia ensiformis (Jack bean), Type IX (powder, 50,000-100,000 units $\mathrm{g}^{-1}$ solid), trypsin from bovine pancreas (Type I, 10,000 BAEE units $\mathrm{mg}^{-1}$ protein), 2-(Dimethylamino)ethyl methacrylate (98\%), methyl red (crystalline), Nile blue acrylamide, Rhodamine B isothiocyanate (mixed isomers, BioReagent, suitable for protein labelling), dimethyl sulphoxide, and Chloroform-D1 (deuteration degree min. 99.8\% for NMR 
spectroscopy) were purchased from Sigma Aldrich. N-isopropyl acrylamide (97\%) was purchased from Sigma and recrystallised from hexane. 2-Hydroxypropyl methacrylate was purchased from Sigma Aldrich and was purified by silica column chromatography, employing n-hexane : ethyl acetate 90:10. Urea (powder, BioReagent for molecular biology, suitable for cell culture) was purchased from Sigma Aldrich and recrystallised from ethanol. Dichloromethane (99.9\%), ethanol (99.9\%), tetrahydrofuran (99.9\%), dimethylformamide ( $>99.8 \%)$, magnesium sulphate (99.6\%), sodium sulphate ( $99.8 \%)$, sodium hydroxide ( $\geq 99 \%$ ), and sodium chloride ( $\geq 99 \%$ ) were purchased from VWR Chemicals. Lithium Phenyl $(2,4,6$ trimethylbenzoyl)phosphinate ( $>98 \%$ ) was purchased from TCl Chemicals UK. Dulbecco's Phosphate Buffered Saline was purchased from Gibco. AIBN was purchased from Molekula and recrystallised from methanol. Biobeads S-X3 (600-14000 $\mathrm{g} \mathrm{mol}^{-1}$ range) was purchased from Bio-Rad Laboratories. Phosphate buffered saline was purchased from Gibco. Ultrapure water was obtained from a Triple Red Avidity Science Duo at $18.2 \mathrm{~m} \Omega \mathrm{cm}^{-1}$.

Ultraviolet-Visible (UV-Vis) spectroscopy was carried on a Molecular Devices Spectramax M5 plate reader.

Polymer molecular weight $\left(\mathrm{M}_{\mathrm{n}, \mathrm{GPC}}\right)$ and dispersity $(\Theta)$ were measured using a 1260 Infinity II GPC MDS (refractive index detection only) equipped with a PSS GRAM guard column ( $8 \times 50 \mathrm{~mm}, 10 \mu \mathrm{m})$ and two PSS GRAM linear columns $(8 \times 300 \mathrm{~mm}, 10 \mu \mathrm{m}, 500-1000000 \mathrm{Da})$ and utilising HPLC grade DMF (containing $0.075 \% \mathrm{wt} \% \mathrm{LiBr}$ ) at $40^{\circ} \mathrm{C}$ as eluent (flow rate of $1 \mathrm{~mL} / \mathrm{min}$ ). Molecular weight calibration was performed using near-monodisperse poly(methyl methacrylate) standards (EasiVial, Agilent).

Dynamic light scattering was used to determine the hydrodynamic diameter $\left(D_{h}\right)$ and polydispersity of the nanoreactors, in ultrapure water and was measured using the Zetasizer Nano ZS. The scattering angle was fixed at $173^{\circ}$. Data processing was carried out using cumulant analysis of the experimental correlation function, and the Stokes-Einstein equation was used to calculate the hydrodynamic radii. All solutions were analysed using disposable poly(styrene) ZEN0040 microcuvettes.

Light stimulation of the DASA was performed by a Teleopto LAD-1 LED array driver powering a LEDA-G $(\lambda=530 \mathrm{~nm})$ LED array. Photopolymerisation to yield the PISA-urease nanoreactors was performed by a Teleopto LAD-1 LED array driver powering a LEDA-V $(\lambda=405 \mathrm{~nm})$ LED array.

Attenuated Total Reflection Fourier-Transform Infrared (ATR-FTIR) spectra was recorded on a Perkin Elmer Spectrum 100 FT-IR spectrometer equipped with a diamond crystal insert.

${ }^{1} \mathrm{H}$ NMR was recorded on a Bruker Avance III HD $600 \mathrm{MHz}$ at $298 \mathrm{~K}$ employing the standard Bruker pulse programs and parameter sets. For diffusion-edited ${ }^{1} \mathrm{H}$ NMR spectra $40 \%$ gradient strengths were applied to selectively suppress the signals of low molecular weight species. The proton signals were referenced internally with residual resonances of the solvent. ${ }^{19} \mathrm{~F} \mathrm{NMR}$ was recorded on a Jeol $400 \mathrm{MHz}$ spectrometer. All measurements were carried in $\mathrm{CDCl}_{3}$. 
$\mathrm{pH}$ measurements were performed with an InLab micro $\mathrm{pH}$-electrode connected to a Mettler Toledo FiveEasy plus $\mathrm{pH}$-meter.

Photographic imaging of the hydrogels in 96-well microplates was performed employing a fully polarised Firefly DE300 Polarizing Handheld USB Digital Dermatoscope. Images were recorded every 5 min.

Measurement of object distances was performed by employing ImageJ (1.52n, Wayne Rasband, National Institutes of Health, USA, Java 1.9.0_172 (64-bit)).

For cryo-TEM, 3.0 $\mu$ of the samples were applied to either glow-discharged Quantifoil R2/2 holey carbon grids (Quantifoil Micro Tools GmbH, Großlöbichau, Germany) or 400 mesh Cu-grids (TAAB Laboratories Equipment Ltd, Aldermaston, England) covered with an additional thin continuous carbon film. Frozenhydrated specimens were prepared with an automatic plunge freezer FEI Vitrobot (Thermo Fisher Scientific, Waltham, MA, USA) operated at $16^{\circ} \mathrm{C}$ and $100 \%$ relative humidity. The samples were incubated $10 \mathrm{sec}$ on the grids, blotted for 3 to $4 \mathrm{sec}$ and plunged into liquid ethane. The cryo-specimens were transferred to a JEOL JEM-2100f transmission electron microscope (JEOL Ltd., Tokyo, Japan) operated at $200 \mathrm{kV}$. Images were recorded using TVIPS TemCam-XF416 CMOS camera (Tietz Video and Image Processing Systems $\mathrm{GmbH}$, Gauting, Germany). Brightness and contrast correction of the images was performed by employing Image $\mathrm{J}$, as well as the measurement of object distances.

Fluorescence correlation spectroscopy was performed using a commercial LSM 880 (Carl Zeiss, Jena, Germany). The incubation chamber was held at $37^{\circ} \mathrm{C}$. A $561 \mathrm{~nm}$ wavelength excitation source ( $\mathrm{HeNe}$ laser) was used in combination with an appropriate filter set and a 40x C-Apochromat water immersion objective (numeric aperture of 1.2). $5 \mu \mathrm{l}$ droplets of sample were pipetted onto glass-bottom ibidi 8-well plates (80827, ibidi, Germany). The laser focus was then moved $200 \mu \mathrm{m}$ above the glass plate to conduct the FCS measurements. Sulforhodamine B (SRB) in PBS was used to calibrate the beam waist $(D=4.14 \mathrm{x}$ $10^{-6} \mathrm{~cm}^{2} / \mathrm{s}$ (SRB) at $25^{\circ} \mathrm{C}$ was used to calculate $D=5.54 \times 10^{-6} \mathrm{~cm}^{2} / \mathrm{s}$ at $\left.37^{\circ} \mathrm{C}\right) .{ }^{51} 30 \times 5$ s intensity traces were measured per sample, whilst the average correlation curves across the whole measurements (150 s) are given in the figures. ZEN software (Carl Zeiss, Jena, Germany) automatically auto-correlated the data and after exporting, the data was fitted using PyCorrfit program 1.1.6. ${ }^{52}$ employing one component fits:

$$
G_{1 \text { comp }}(\tau)=\left(1+\frac{T}{1-T} e^{\frac{-\tau}{\tau_{\text {trip }}}}\right) * \frac{1}{N *\left(1+\frac{\tau}{\tau_{D}}\right) * \sqrt{1+\frac{\tau}{S P^{2} \tau_{D}}}}
$$

The height to waist ratio (structural parameter $S P$ ) was fixed to $5 .{ }^{\tau_{\text {trip }}}$ is the triplet time with corresponding triplet fraction ${ }^{T}$, and $\tau_{D}$ is the diffusion time, $N$ is the number of diffusing species in the confocal volume. A solution of SRB in PBS was measured to calibrate the $x$-y dimension of the confocal volume $\left(\omega_{x y}^{2}\right)$. Using the obtained diffusion times $\left({ }^{\tau_{D}}\right)$ from above, the diffusion coefficients $\left({ }^{D}\right)$ were subsequently obtained for each unknown sample: 


$$
D=\frac{\omega_{x y}^{2}}{4 \tau_{D}}
$$

The Einstein-Stokes equation was subsequently employed to calculate hydrodynamic radii $\left(R_{h}\right)$ using the obtained diffusion coefficients $\left(^{D}\right)$ from above. Numbers of cargo per polymersome was calculated by dividing the counts per particle (CPP) obtained for loaded polymersomes by the value obtained for free labelled cargo.

\section{Synthesis of pentafluorophenyl acrylate (PFPA)}

The compound was synthesised following a procedure published by Théato and co-workers. ${ }^{53}$

\section{Synthesis of poly(ethylene glycol)-b-(poly(butyl acrylate)-co-poly(pentafluorophenyl acrylate)) (1)}

Chain extension by reversible addition fragmentation chain-transfer (RAFT) radical polymerisation was performed on the macro chain-transfer agent (macroCTA) poly(ethylene glycol) 4-cyano-4-

(phenylcarbonothioylthio) pentanoate (PEG-CPADB), yielding an amphiphilic diblock copolymer with a randomly distributed activated ester. AIBN $(1.0 \mathrm{mg}, 6.09 \mu \mathrm{mol})$ and PEG-CPADB $(97.4 \mathrm{mg}, 48.7 \mu \mathrm{mol})$ were dissolved together in $0.77 \mathrm{~mL}$ of 1,4-dioxane. In parallel, butyl acrylate (BA) was purified from monomethyl ether hydroquinone by perfusion through a basic aluminium oxide plug. Then, pentafluorophenyl acrylate (PFPA) $(50.2 \mu \mathrm{L}, 72.5 \mathrm{mg}, 0.3 \mathrm{mmol})$ and the purified BA $(0.39 \mathrm{~mL}, 0.35 \mathrm{~g}, 2.74$ $\mathrm{mmol}$ ) was added to the initiator and macroCTA solution. Oxygen was removed from the resulting solution by bubbling with argon flow for $1 \mathrm{~h}$. The stoichiometry I:CTA:M was 1:8:500 and the monomer ratio BA:PFPA was 9:1. The reaction was initiated by exposing the solution to $90^{\circ} \mathrm{C}$ in argon atmosphere. The reaction was ended after $3 \mathrm{~h}$ by exposure to atmospheric oxygen. The polymer was purified by precipitation in 60:40 v/v methanol:water. The resulting suspension was centrifuged at $7000 \mathrm{~g}$ for $15 \mathrm{~min}$ at room temperature (Eppendorf 5430/5430R, F-35-6-30 rotor). To remove the remaining non-polymerised monomer, the pellet was dissolved in $2 \mathrm{~mL}$ of THF and an end of spatula of Sudan Blue II was added as a small molecule indicator for preparative size exclusion chromatography (SEC). SEC was performed employing Biobeads S-X3 (600-14000 $\mathrm{g} \mathrm{mol}^{-1}$ range) as the stationary phase and distilled THF as the mobile phase. The elution volume prior to the blue small molecule indicator fraction was collected and concentrated in vacuo. After further drying the polymer in a vacuum oven at $40{ }^{\circ} \mathrm{C}$ overnight, $360 \mathrm{mg}(69$ $\%$ yield) was collected.

\section{Removal of chain-transfer agent end-group from PEG-b-(PBA-co-PPFPA) (2)}

The chain-transfer agent was removed from PEG- $b$-(PBA-co-PPFPA) following a procedure reported by Perrier et al. ${ }^{54}$ The polymer $(360 \mathrm{mg})$ was dissolved with $200 \mathrm{mg}(1.2 \mathrm{mmol})$ of AIBN in DMF $(3 \mathrm{~mL})$ in a round bottom flask. The solution was bubbled for $1 \mathrm{~h}$ with nitrogen flow and posteriorly sealed under nitrogen atmosphere. The reaction was initiated by transferring the solution to an $80^{\circ} \mathrm{C}$ oil bath and carried for 4 hours. The polymer was posteriorly purified by SEC. For this purpose, an end of spatula of 
Sudan Blue II was added as an indicator for the small molecule fraction, and Biobeads S-X3 (600-14000 g $\mathrm{mol}^{-1}$ range) was employed as the stationary phase, using distilled THF as eluent. The organic solution was collected prior to the appearance of the Sudan Blue II fraction and was concentrated in vacuo. The polymer, was further dried in a vacuum oven overnight at $40{ }^{\circ} \mathrm{C}$.

\section{Synthesis of the $2^{\text {nd }}$ generation DASA donor precursor N-(4-methoxyphenyl)-1,3-diaminopropane (MPDP)}

The compound was synthesised following a procedure published by Han and co-workers. ${ }^{55}$

\section{Synthesis of aromatic amine DASA precursor diblock copolymer (3)}

The AIBN-capped PEG- $b$-(PBA-co-PPFPA) was dissolved in anhydrous DMF ( $3 \mathrm{~mL})$ together with MPDP $\left(100 \mathrm{mg}, 5.5 \cdot 10^{-1} \mathrm{mmol}\right)$ and triethylamine $(0.10 \mathrm{~mL}, 0.73 \mathrm{mg}, 1 \mathrm{mmol})$. The solution was degassed by bubbling with $\mathrm{N}_{2}$ flow for $30 \mathrm{~min}$. The reaction was carried at $60^{\circ} \mathrm{C}$ for 12 hours. Subsequently, the polymer was purified by SEC employing an end of spatula of Sudan Blue II as an indicator for the small molecule fraction. The reaction mixture was poured onto Biobeads S-X3 (600-14000 g mol${ }^{-1}$ range) and the polymer was eluted with distilled THF. The volume prior to the apparition of the blue small molecule fraction was collected, concentrated in vacuo and dried in a vacuum oven at $40^{\circ} \mathrm{C}$ overnight.

\section{Synthesis of Meldrum's acid-based furan adduct}

The compound was synthesised according to a procedure described by Read de Alaniz and co-workers. ${ }^{56}$

\section{Modification of aromatic amine DASA precursor polymer to yield the DASA polymer}

The secondary aromatic amine on the diblock copolymer (3) was reacted with the Meldrum's acid-based furan adduct to yield the DASA diblock copolymer. In short, $100 \mathrm{mg}\left(1.2 \cdot 10^{1} \mathrm{nmol}\right)$ of the polymer was dissolved in a solution of the Meldrum's acid-based furan adduct $\left(9 \cdot 10^{-1} \mathrm{mmol} \cdot \mathrm{mL}^{-1}\right)$ in a round-bottom flask. The solution was capped with a rubber septum and was allowed to stir at room temperature for 7 days. The polymer was then purified from the excess of furan adduct by SEC. Biobeads S-X3 (600-14000 $\mathrm{g} \mathrm{mol}^{-1}$ range) was employed as the stationary phase and distilled THF as the mobile phase. In this case, the addition of small molecule indicator was not required as both the furan adduct and the polymer presented distinctive colours.

\section{Preparation of DASAesterase nanoreactors}

Unless otherwise stated, $1 \mathrm{mg}\left(2.2 \cdot 10^{-1} \mathrm{nmol}\right)$ of the DASA diblock copolymer was weighted in a HPLC vial and dissolved in $0.1 \mathrm{~mL}$ of 1,4-dioxane. The self-assembly was conducted in a dimly lit room to favour the triene-enol form of the DASA, i.e., its more hydrophobic and colourful state. In a different HPLC vial $1 \mathrm{mg}$ of esterase from porcine liver $(5.95 \mathrm{nmol})$ was dissolved in $1 \mathrm{~mL}$ of ultrapure water and equipped with a magnetic stir bar. The solution was stirred at level 2 of a Stuart UC151 hot plate, and the polymer solution was added gradually in $10 \mu \mathrm{L}$ steps. The resulting dispersion was allowed to stir for 
another five minutes. To digest the non-encapsulated esterase, the dispersion was transferred to a third HPLC vial containing $0.5 \mathrm{mg}$ of trypsin $(21 \mathrm{nmol})$ and incubated at $37^{\circ} \mathrm{C}$ overnight. Finally, the sample was stored at $4{ }^{\circ} \mathrm{C}$.

To facilitate cryo-TEM imaging, $2 \mathrm{mg}\left(2.2 \cdot 10^{-1} \mathrm{nmol}\right)$ of the of the DASA block copolymer was employed instead of $1 \mathrm{mg}$.

\section{Synthesis of urease loaded polymersomes by polymerisation induced self-assembly (PISA)}

Synthesis of PEG ${ }_{113}-C D T P A$. CDTPA $\left(0.97 \mathrm{~g}, 2.4 \mathrm{mmol}^{-}, \mathrm{PEG}_{113}\left(\mathrm{M}_{\mathrm{n}}=5000 \mathrm{~g} \mathrm{~mol}^{-1}\right)(6 \mathrm{~g}, 1.2 \mathrm{mmol})\right.$ and DCM $(20 \mathrm{~mL})$ were charged to a round bottom flask equipped with a stir bar. Then, a solution of DCC (0.5 $\mathrm{g}, 2.4 \mathrm{mmol})$ and DMAP $(0.029 \mathrm{~g}, 0.24 \mathrm{mmol})$ in DCM $(10 \mathrm{~mL})$ was added dropwise to the reaction flask which was maintained at $0{ }^{\circ} \mathrm{C}$ using an ice-water bath. The flask was subsequently sealed with a rubber septum and purged with nitrogen for $30 \mathrm{~min}$ at $0{ }^{\circ} \mathrm{C}$. The esterification reaction was allowed to proceed with stirring at room temperature for $48 \mathrm{~h}$ in the dark. The yellow polymer was collected by three repeated precipitation/centrifugation $(7000 \times \mathrm{g}$ for $5 \mathrm{~min}$ ) cycles of the reaction mixture in cold diethyl ether.

Synthesis of urease loaded PEG $113^{-b-P H P M A}$ polymersomes. $\mathrm{PEG}_{113}$-CDTPA (5.67 mg, $\left.1.05 \mu \mathrm{mol}\right)$, HPMA $\left(60.3 \mu \mathrm{g}, 56.6 \mu \mathrm{L}, 4.18 \cdot 10^{-4} \mathrm{mmol}\right)$ and $441.2 \mu \mathrm{L}$ of Jack Bean urease $\left(10 \mathrm{mg} \mathrm{mL}^{-1}\right)$ in PBS was added to a $2.5 \mathrm{~mL}$ crimp vial equipped with a magnetic stir bar. The vial was sealed and degassed by bubbling with $\mathrm{N}_{2}$ flow for $30 \mathrm{~min}$. The vial was then irradiated using an LED array $\left(\lambda_{\max }=405 \mathrm{~nm}, 1 \sim 10 \mathrm{~mW} \cdot \mathrm{cm}^{-2}\right)$ for 3 hours with magnetic stirring. To purify the polymersome samples, the turbid solution was removed from the light source, diluted 10 times with $\mathrm{ddH}_{2} \mathrm{O}$ and spun at $16000 \times \mathrm{g}$ for $10 \mathrm{~min}$. The supernatant was carefully removed and the polymersome pellet resuspended in $5 \mathrm{~mL}$ of fresh ultrapure water. The centrifugation process was repeated an additional two times to obtain the purified urease loaded PEG- $b$ PHPMA polymersomes (PISA-urease).

\section{Fluorescent dye functionalisation of enzymes and preparation of samples for Fluorescence Correlation Spectroscopy (FCS) measurements}

Functionalisation of esterase and urease with Rhodamine B-isothiocyanate. $0.33 \mathrm{mg}\left(6.1 \cdot 10^{-1} \mu \mathrm{mol}\right)$ of rhodamine B isothiocyanate was weighted in a $1.5 \mathrm{~mL}$ screw HPLC vial and dissolved in $33 \mu \mathrm{L}$ of DMSO. In a separate HPLC vial, either $2 \mathrm{mg}(11.9 \mathrm{nmol})$ of esterase or $2 \mathrm{mg}(3.7 \mathrm{nmol})$ of urease was dissolved in $400 \mu \mathrm{L}$ of ultrapure water and equipped with a magnetic stirrer bar. The organic solution was transferred to the aqueous protein solution. The vial was covered in aluminium foil and the reaction was allowed to proceed for $2 \mathrm{~h}$ whilst stirring. The labelled esterase (RhB-esterase) was purified by size exclusion chromatography, employing two sequential PD Minitrap ${ }^{\mathrm{TM}}$ G-25 and PD Miditrap ${ }^{\mathrm{TM}}$ G-25 (GE Healthcare). In the case of urease, the solution was dialysed against $1 \mathrm{~L}$ of ultrapure water by employing a Float-Alyzer $\mathrm{G} 2$ dialysis device $\left(\mathrm{MWCO}=100000 \mathrm{~g} \mathrm{~mol}^{-1}\right)$. The elution volume was exchanged once per day throughout 4 days. In both cases, the labelled protein powders were concentrated by lyophilisation (RhBesterase: 1.3 mg, 65 \% yield; RhB-urease: 1.8 mg, 90 \% yield). 
Preparation trypsinised RhB-esterase. Aqueous solutions of RhB-esterase $\left(1 \mathrm{mg} \mathrm{mL}^{-1}\right)$ were incubated with trypsin $\left(0.3 \mathrm{mg} \mathrm{mL}^{-1}\right)$ at $35^{\circ} \mathrm{C}$ for $12 \mathrm{~h}$ to induce protein digestion.

PISA polymersomes loaded with rhodamine B-modified urease. To generate PISA-RhB-urease, a solution of $9 \mathrm{mg} \mathrm{mL}^{-1}$ of commercial urease and $1 \mathrm{mg} \mathrm{mL}^{-1}$ of RhB-urease was prepared and all other reaction conditions for the synthesis of PISA-urease were employed.

\section{Photoswitching and thermal recovery measurements of the DASA polymer}

\section{Photoswitching of the DASA polymer in THF}

A solution of $24 \mu \mathrm{g} \mathrm{mL}^{-1}$ of the DASA polymer in THF was introduced in a $1 \mathrm{~mL}$ quartz cuvette. UV-Vis measurements were performed at $530 \mathrm{~nm}$ on the cuvette holder of a Spectramax M5 (Molecular Devices). After an initial measurement, the samples were irradiated for $30 \mathrm{sec}$ at $530 \mathrm{~nm}$ at intensities of either 0.23 $\mathrm{mW} \cdot \mathrm{cm}^{-2}, 0.76 \mathrm{~mW} \cdot \mathrm{cm}^{-2}$, or $1.49 \mathrm{~mW} \cdot \mathrm{cm}^{-2}$. The thermal recovery was monitored over $15 \mathrm{~min}$ every 10 sec. This process was repeated 3 times. The experiments were carried out in triplicate and the values of the three cycles were normalised to the maximum absorbance of the first cycle. Finally, the data was laid in sequence.

\section{Photoswitching of aqueous DASA polymer dispersions}

In this case, the organic solution was substituted by a dispersion of $0.05 \mathrm{mg} \mathrm{mL}^{-1}$ of the DASA polymer in ultrapure water. $150 \mu \mathrm{L}$ of this dispersion was transferred to a Corning 96-well half-area microplate (poly(styrene), non-binding). Data acquisition and treatment was performed in the same manner as the polymers in organic solution. In this case, the samples were irradiated at $0.76 \mathrm{~mW} \cdot \mathrm{cm}^{-2}$, or $1.49 \mathrm{~mW} \cdot \mathrm{cm}^{-}$ 2 , and $2.12 \mathrm{~mW} \cdot \mathrm{cm}^{-2}$ for $10 \mathrm{~min}$, and the thermal recovery was monitored over 30 min every $10 \mathrm{sec}$.

\section{Determination of esterase activity of DASAesterase nanoreactors}

$5 \mu \mathrm{L}$ of 100 times diluted DASA-esterase dispersion was introduced in $295 \mu \mathrm{L}$ of an aqueous solution of MR $\left(7.4 \cdot 10^{-1} \mu \mathrm{mol} \cdot \mathrm{mL}^{-1}\right)$ and saturated ethyl acetate $(\mathrm{pH}=7.8)$ contained in a Corning 96-well microplate (poly(styrene), non-binding). The plate was placed in the measuring tray of a plater reader (Spectramax M5, Molecular Devices) and an initial UV-Vis measurement at $530 \mathrm{~nm}$ was performed. The 96-well plate was irradiated with light at $530 \mathrm{~nm}$. The sample was irradiated at intensities of either $0.76 \mathrm{~W}$ $\mathrm{cm}^{-2}$ or $1.49 \mathrm{~W} \mathrm{~cm}^{-2}$. UV-Vis measurements were taken at $530 \mathrm{~nm}$ every $10 \mathrm{~min}$ over $160 \mathrm{~min}$. In the case of non-stimulated nanoreactors, absorbance measurements were performed as kinetics at $530 \mathrm{~nm}$ every $10 \mathrm{~min}$ for a period of $160 \mathrm{~min}$.

\section{Evaluation of urea hydrolysis by PISA-urease nanoreactors}

$1 \mu \mathrm{L}$ of a PISA-urease dispersion was introduced in $295 \mu \mathrm{L}$ of an aqueous solution of MR $\left(7.4 \cdot 10^{-1}\right.$ $\left.\mu \mathrm{mol} \cdot \mathrm{mL}^{-1}\right)$, urea $\left(8.3 \cdot 10^{-1} \mathrm{mmol} \cdot \mathrm{mL}^{-1}\right)$, and saturated ethyl acetate $(\mathrm{pH}=7.8)$ contained in a Corning 
96-well microplate (poly(styrene), non-binding). The plate was placed in the measuring tray of a plate reader (Spectramax M5, Molecular Devices) and kinetics measurements were taken at $530 \mathrm{~nm}$ every 10 sec over 40 min.

\section{Synthesis of PNIPAAm-co-PDMAEMA-co-PNBA gels}

N-isopropyl acrylamide (NIPAAm) (200 mg, $1.76 \mathrm{mmol})$, 2-dimethylaminoethyl methacrylate (DMAEMA) (0.57 mL, $538 \mathrm{mg}, 3.4 \mathrm{~mol})$, N,N'-methylenebisacrylamide $\left(9.75 \mathrm{mg}, 6.32 \cdot 10^{-2} \mathrm{mmol}\right)$, Nile blue acrylamide (1 mg, $2.45 \mu \mathrm{mol}$ ), Lithium phenyl-2,4,6-trimethylbenzoylphosphinate (LAP) (2 mg, $1.17 \mathrm{mmol}$ ), and poly(ethylene glycol) (PEG) $\mathrm{M}_{\mathrm{n}} \sim 2000 \mathrm{~g} \mathrm{~mol}^{-1}$ were dissolved in $250 \mu \mathrm{L}$ of ultrapure water. $60 \mu \mathrm{L}$ of this solution was deposited between 2 PDMS discs (diameter $=2 \mathrm{~cm}$ ) and placed under a UV lamp at $365 \mathrm{~nm}$ for $10 \mathrm{~min}$. Then, the discs were separated and immersed in a water bath overnight to promote the separation of the gel from the PDMS disc and the elution of impurities. Smaller gels were cut out with a 2 $\mathrm{mm}$ biopsy punch to be employed for light mediated swelling and de-swelling experiments.

\section{Data Availability}

Raw data are available upon request from rdm-enquiries@imperial.ac.uk.

\section{Figures}

A

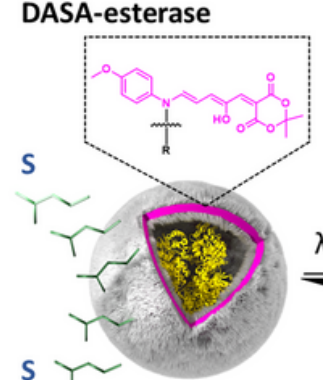

Impermeable membrane

B

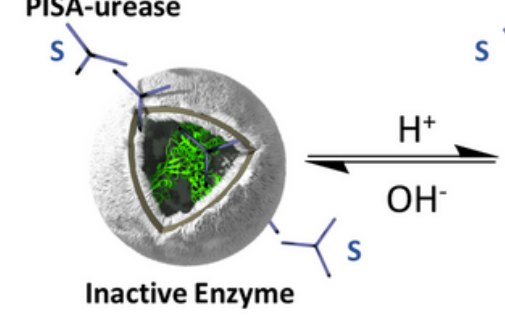

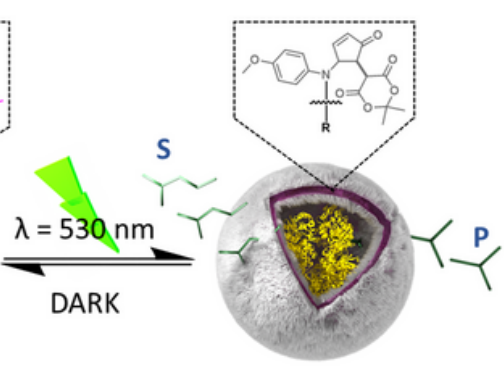

Permeable membrane

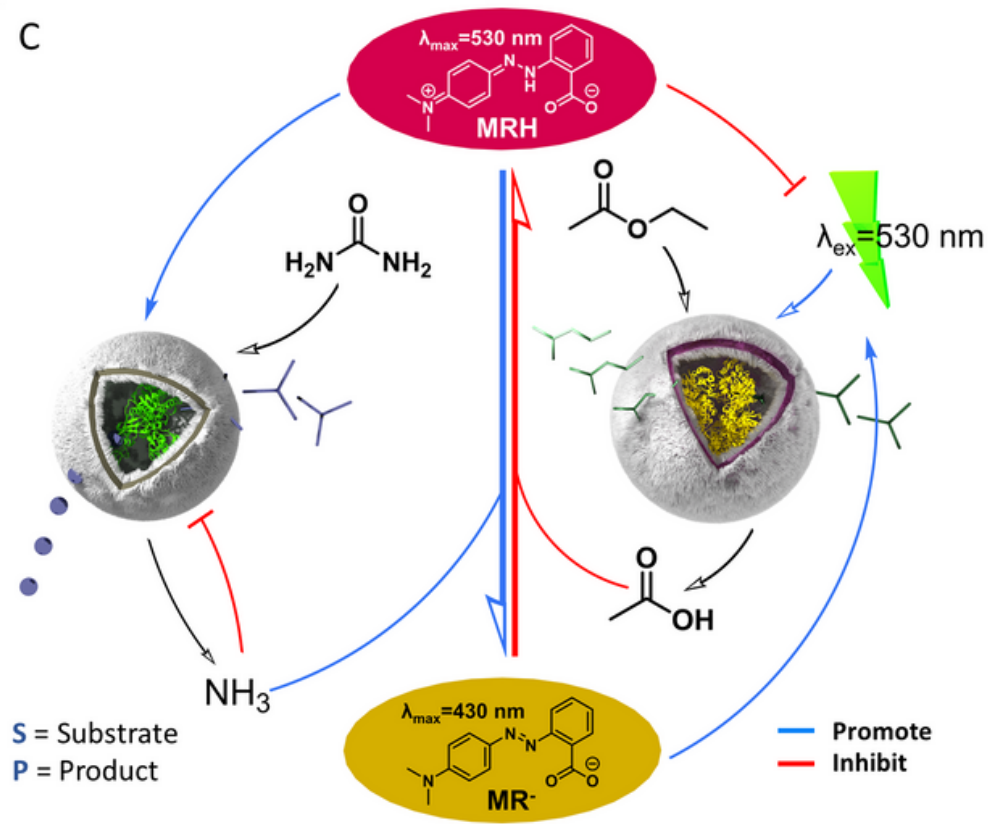

Figure 1

DASA photoswitch driven enzymatic feedback loops between communicating polymersome nanoreactors. A. The catalytic activity of DASA-esterase nanoreactors is switched ON by irradiation of green light and switched OFF by withdrawal of light. B. PISA-urease nanoreactors are permanently permeable to small molecules such as urea and ammonia. The enzyme is optimally active in acidic 
conditions and inactive in basic conditions. C. Negative and positive feedback loops generated between nanoreactors containing antagonistic enzymes. DASA-esterase nanoreactors generate acetic acid by enzymatic hydrolysis of ethyl acetate in the presence of green light. The acid generates MRH, which shifts its absorbance to the green region of the visible spectrum and masks the penetration of further green light, inhibiting its own synthesis. The acidification activates PISA-urease nanoreactors which enzymatically hydrolyse urea into ammonia. The ammonia promotes formation of $\mathrm{MR}^{-}$allowing further penetration of green light and production of acetic acid. The accumulation of ammonia inhibits further hydrolysis from PISA-urease.
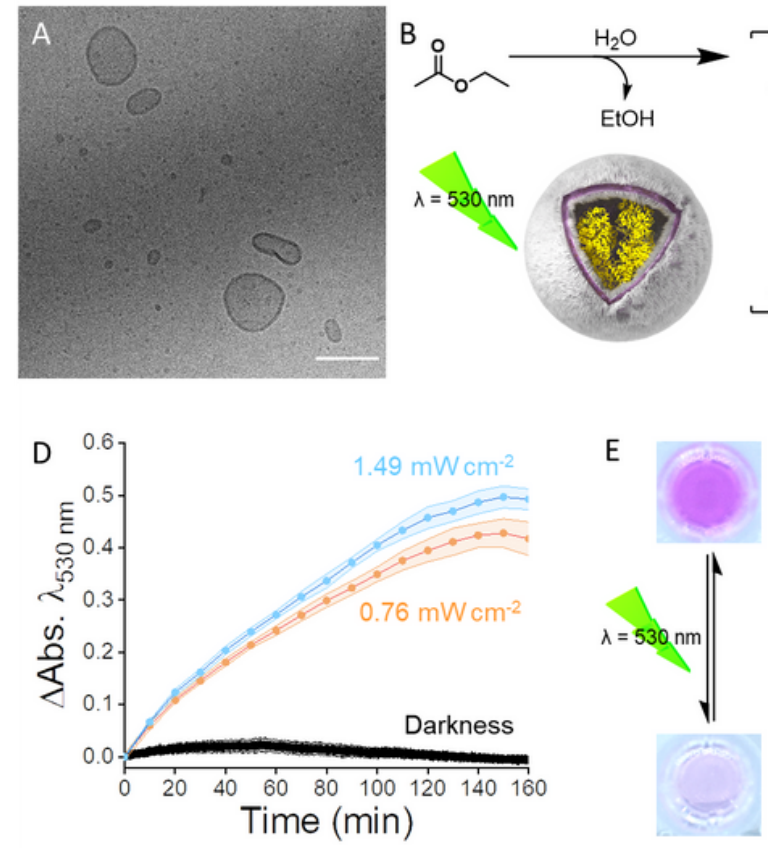
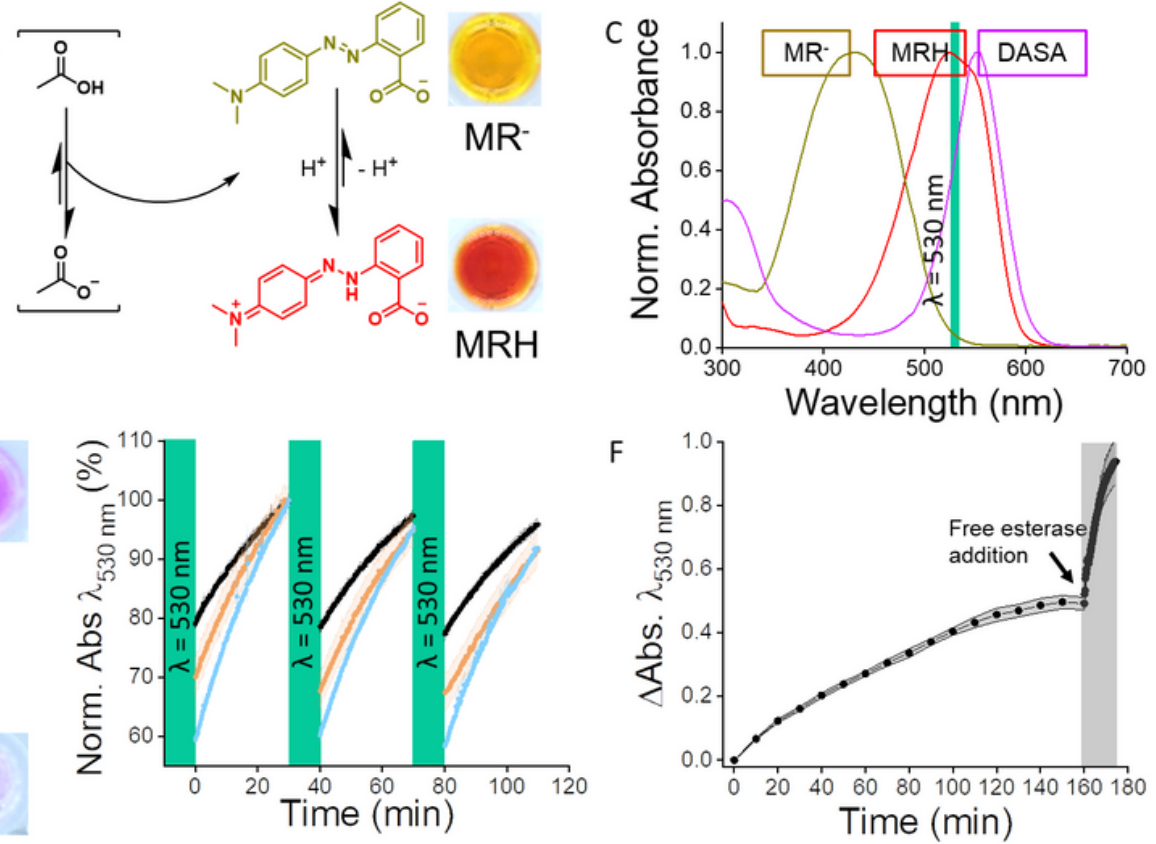

Figure 2

\section{Green light mediated modulation of DASA-esterase catalytic activity and negative feedback loop}

generation. A. Cryo-TEM micrograph of DASA-esterase nanoreactors. The scale bar represents $200 \mathrm{~nm}$. B. Schematic representation of the biocatalytic hydrolysis of ethyl acetate to produce acetic acid by DASAesterase nanoreactors. The production of acid accumulated MRH generating a transition from yellow solutions in basic conditions to red in acidic conditions. C. UV-Vis spectral scans of MR- (yellow), MRH (red), and an organic DASA polymer solution (violet). D. UV-Vis measurements of DASA-esterase nanoreactor mediated biocatalytic hydrolysis of ethyl acetate in the presence of MR by continuous irradiation of green light at $1.49 \mathrm{~mW} \cdot \mathrm{cm}^{-2}$ (blue), $0.76 \mathrm{~mW} \cdot \mathrm{cm}^{-2}$ (orange), and in darkness (black). The protonation of MR was monitored at $530 \mathrm{~nm}(n=3$ technical replicates, mean \pm SD). E. UV-Vis measurements of DASA polymersome photoswitching by alternating irradiation with green light and recovery of absorbance in the dark. In each cycle, the dispersions were irradiated for 10 min and thermal recovery of the absorbance was monitored at $530 \mathrm{~nm}$ for $30 \mathrm{~min}$. The samples were irradiated at light intensities of $0.76 \mathrm{~mW} \cdot \mathrm{cm}^{-2}$ (black), $1.49 \mathrm{~mW} \cdot \mathrm{cm}^{-2}$ (orange), and $2.12 \mathrm{~mW} \cdot \mathrm{cm}^{-2}$ (blue) ( $n=3$ technical replicates, mean $\pm S D$; representative images shown). F. Addition of free esterase after formation of 
plateau mediated by DASA-esterase nanoreactors irradiated with green light. The data in panel D at 1.49 $\mathrm{mW} \cdot \mathrm{cm}^{-2}$ was repeated, with the addition of $60 \mathrm{pmol}$ of free esterase after $140 \mathrm{~min}$ of green light irradiation ( $n=3$ technical replicates, mean \pm SD).
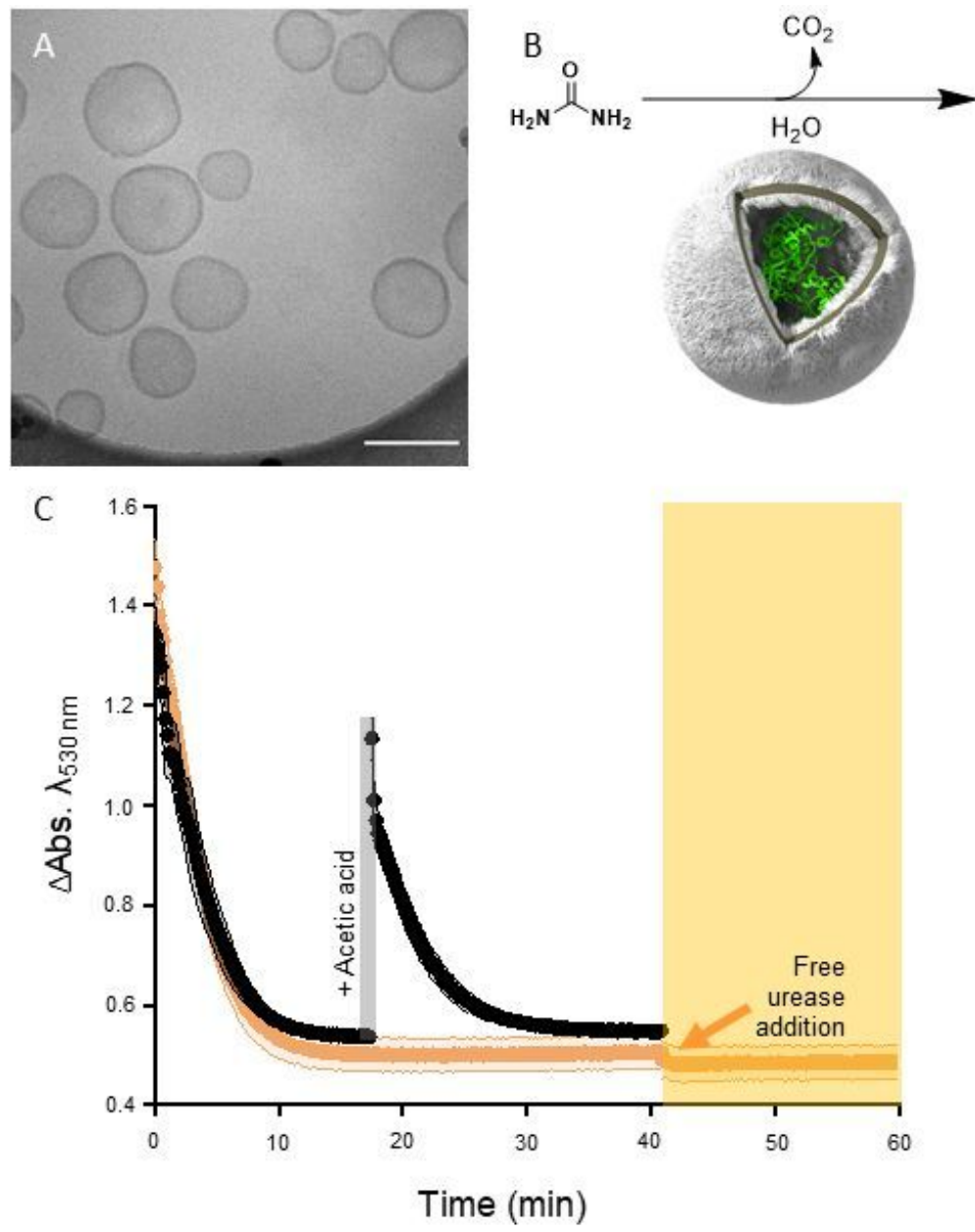
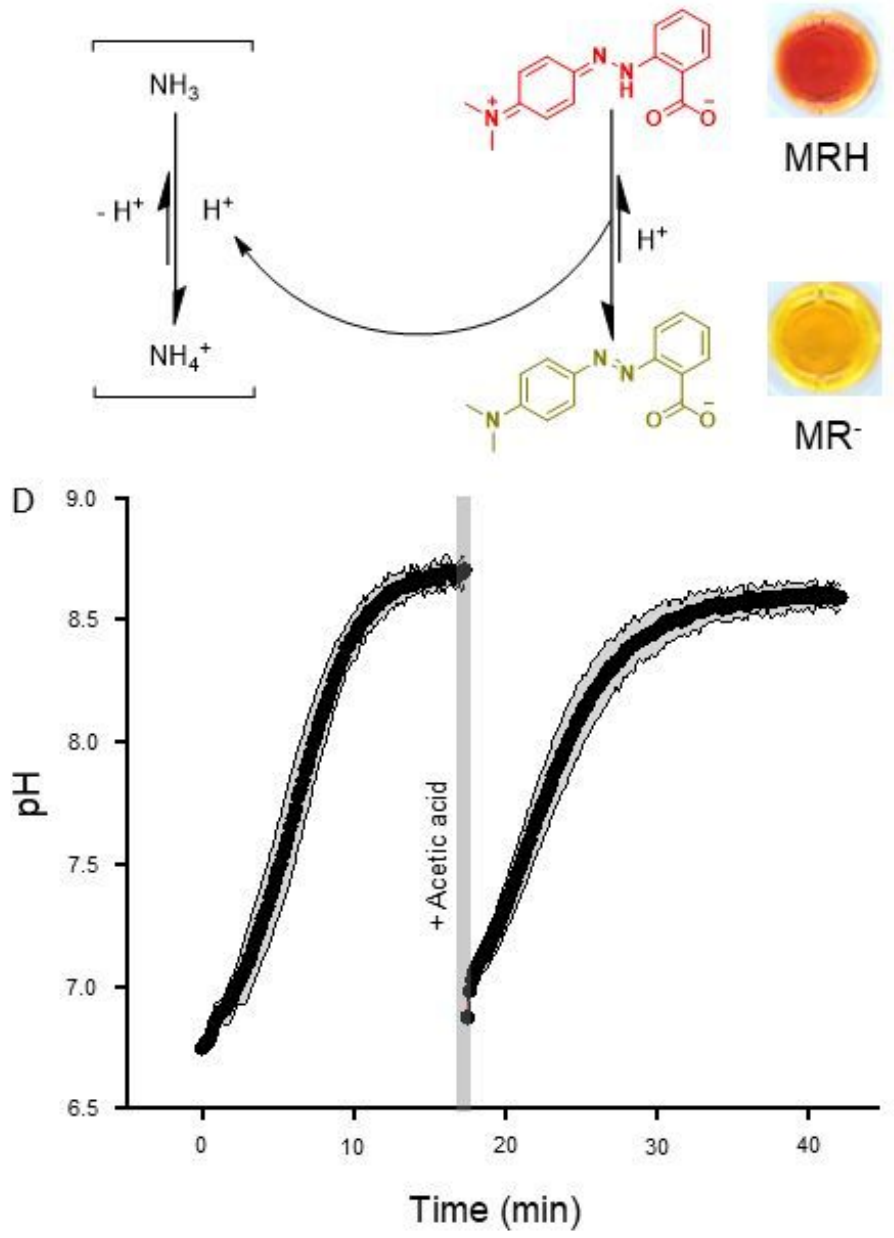

\section{Figure 3}

pH-mediated automodulation of PISA-urease catalytic activity. A. Cryo-TEM micrograph of PISA-urease nanoreactors. The scale bar represents $300 \mathrm{~nm}$. B. Schematic representation of the biocatalytic hydrolysis of urea to produce ammonia by PISA-urease nanoreactors. The production of base produces $\mathrm{MR}^{-}$generating a transition from red solutions in acidic conditions to yellow in basic conditions. C. UV-Vis measurements of PISA-urease mediated biocatalytic hydrolysis of urea. The formation of ammonia was monitored by the production of $\mathrm{MR}^{-}$at $530 \mathrm{~nm}$. Orange: After $40 \mathrm{~min}, 0.17 \mathrm{nmol}$ of free urease was added ( $n=3$ technical replicates, mean \pm SD). Black: The formation of MR $^{-}$was monitored for 17 min, followed by addition of $24 \mathrm{nmol}$ of acetic acid and the production of $\mathrm{MR}^{-}$was monitored again ( $n=3$ technical replicates, mean \pm SD). D. pH monitoring of ammonia formation by PISA-urease nanoreactors calculated from UV-Vis traces (black) in panel C. 
A

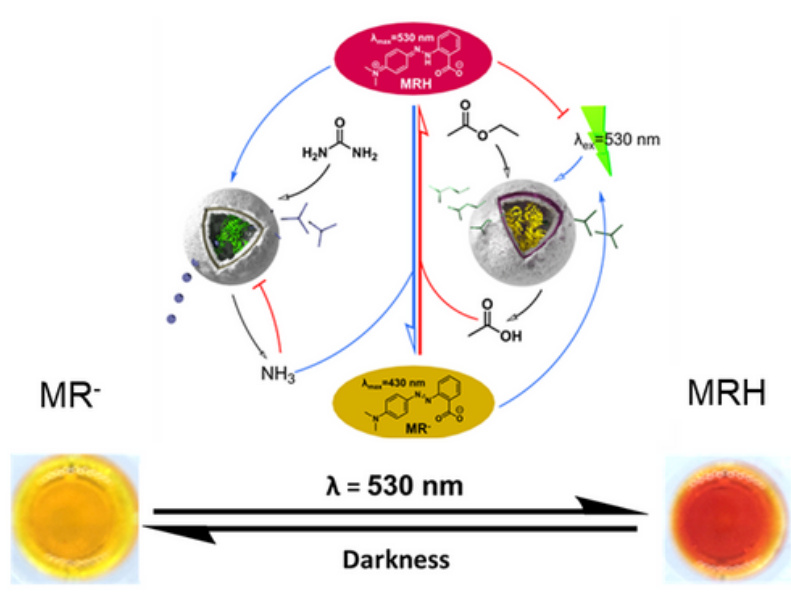

C

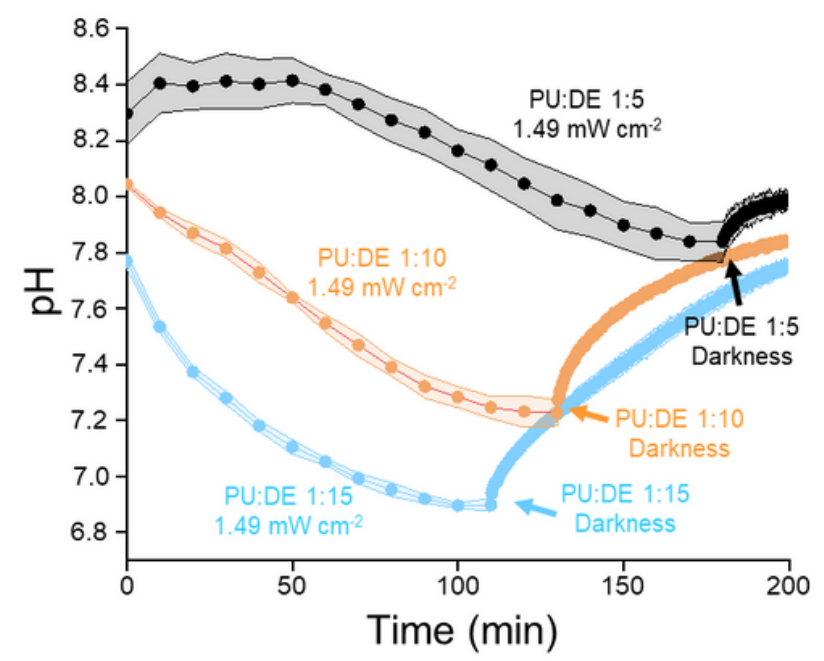

B

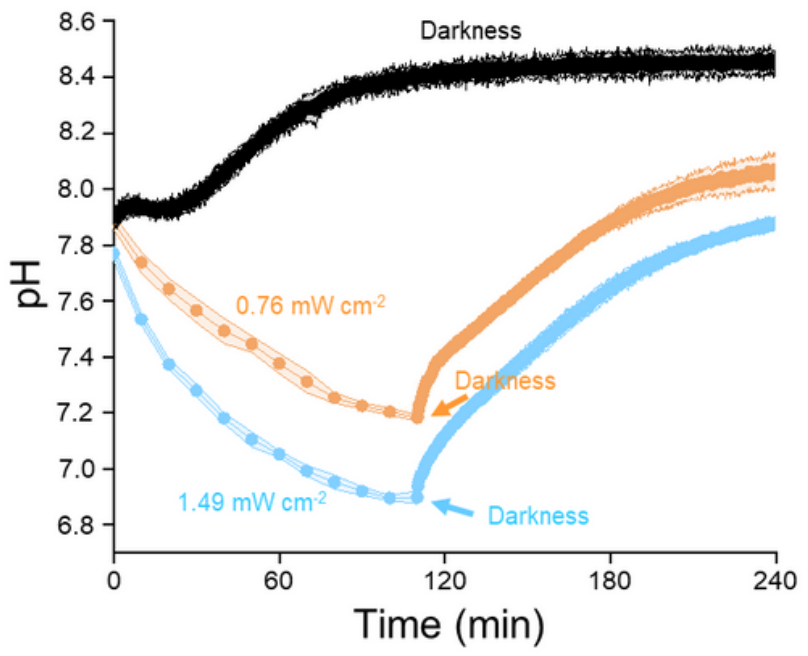

D

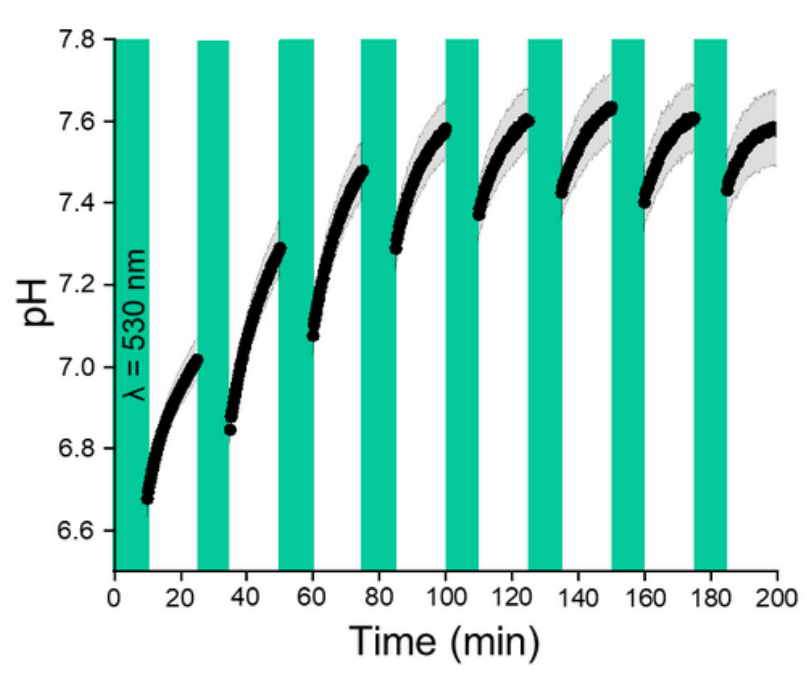

Figure 4

Light-mediated modulation of $\mathrm{pH}$ by chemical communication between DASA-esterase and PISA-urease nanoreactors. A. Schematic representation of out-of-equilibrium MR protonation by modulation of $\mathrm{pH}$ by DASA-esterase and PISA-urease in the presence or absence of light $(\lambda=530 \mathrm{~nm})$. B. Monitoring of $\mathrm{pH}$ evolution in samples containing a PISA-urease (PU) : DASA-esterase (DE) ratio of 1:15 in darkness (black), by continuous irradiation with green light $(\lambda=530 \mathrm{~nm})$ at $0.76 \mathrm{~mW} \cdot \mathrm{cm}^{-2}$ for $110 \mathrm{~min}$ followed by darkness (orange), and $1.49 \mathrm{~mW} \cdot \mathrm{cm}^{-2}$ for $110 \mathrm{~min}$ followed by darkness (blue) ( $n=3$ technical replicates, mean \pm SD). C. Monitoring of $\mathrm{pH}$ evolution by continuous irradiation of green light at $1.49 \mathrm{~mW} \cdot \mathrm{cm}^{-2}$ with volume ratios of PU:DE of 1:5 (irradiation for 180 min followed by darkness) (black), 1:10 (irradiation for 130 min followed by darkness) (orange), and 1:15 (irradiation for 110 min followed by darkness) (blue) ( $n$ $=3$ technical replicates, mean \pm SD). The latter was repeated from Figure 4B for illustration purposes. $\mathbf{D}$. Monitoring of the evolution of $\mathrm{pH}$ by alternating cycles of green light (at $4.31 \mathrm{~mW} \cdot \mathrm{cm}^{-2}$ ) and darkness. In each cycle, the samples were irradiated for $10 \mathrm{~min}$ and the $\mathrm{pH}$ was probed for $15 \mathrm{~min}$ in darkness $(n=3$ technical replicates, mean \pm SD). 
A

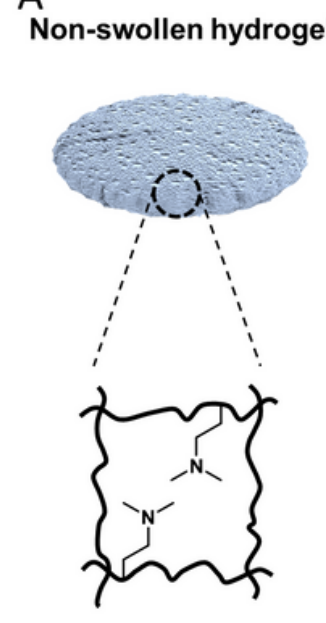

Deprotonated tertiary amine

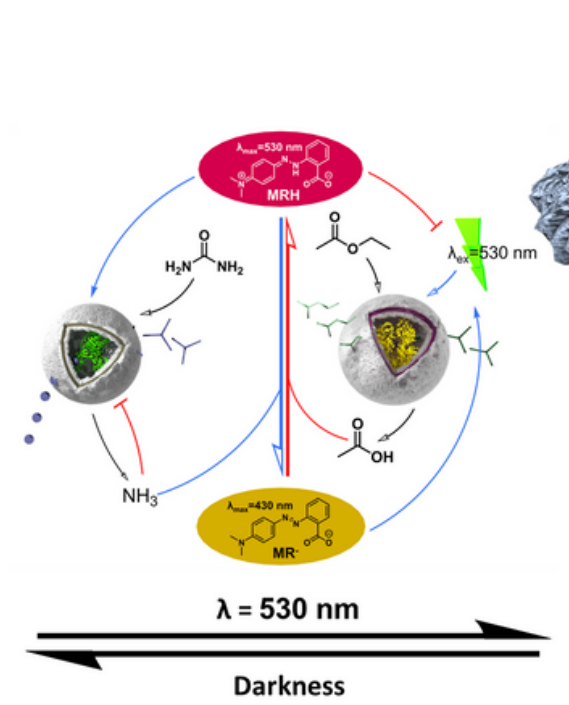

Darkness
D
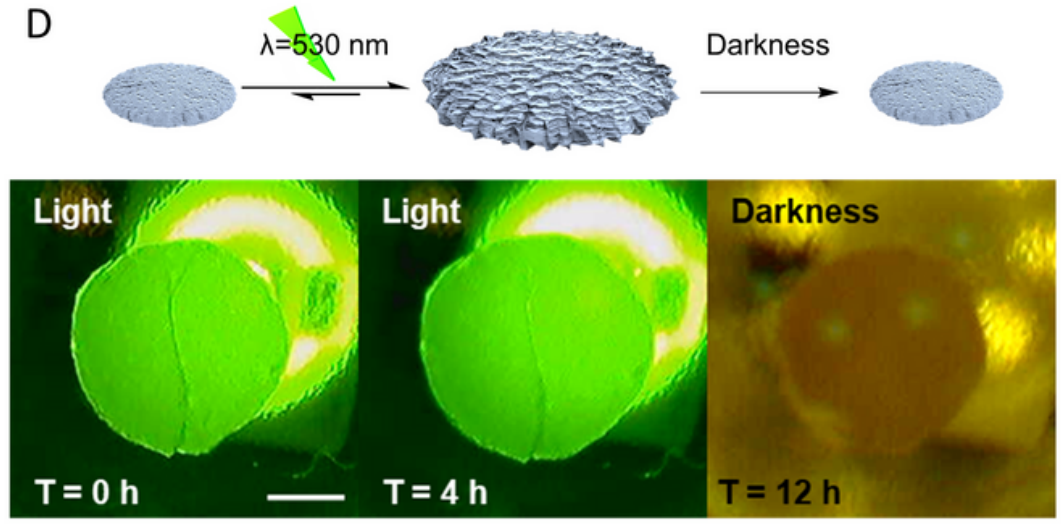
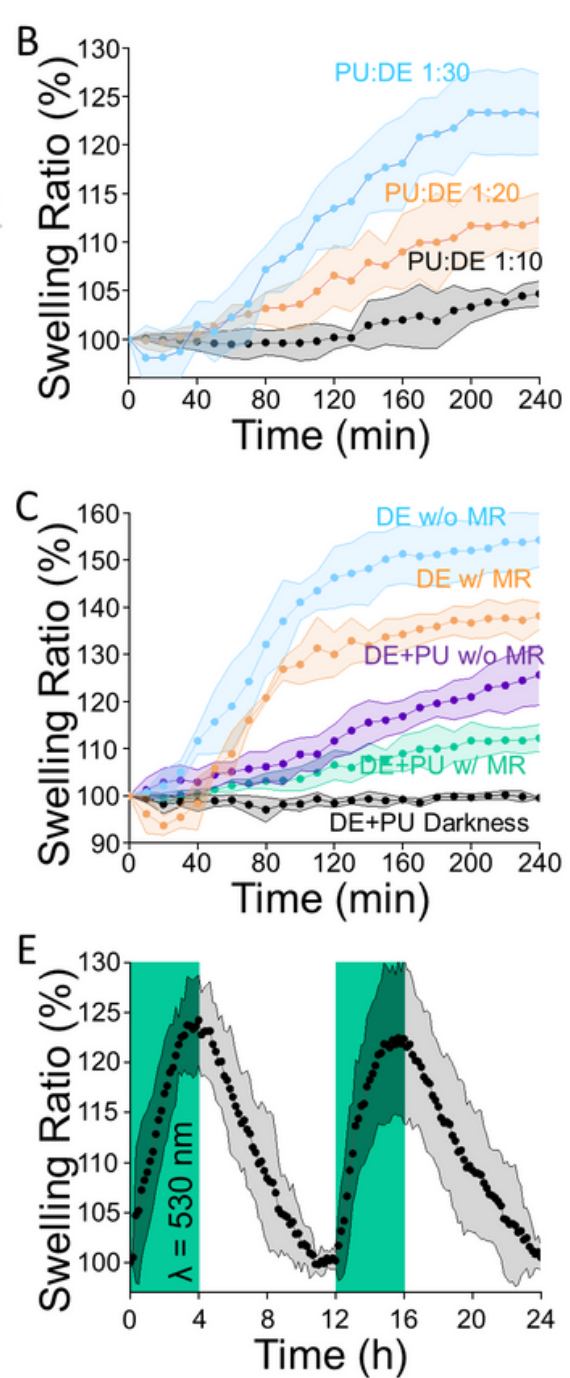

\section{Figure 5}

Modulation of hydrogel swelling by communication between antagonistic nanoreactors. A. Schematic representation of crosslinked PNIPAAm-co-PDMAEMA-co-PNBA hydrogel swelling states. The acidification of the medium in the presence of light induces the protonation of the tertiary aminecontaining hydrogel to induce swelling. In the absence of light, the recovery of alkaline conditions induces the deprotonation of the hydrogel and subsequent de-swelling. B. Quantification of the swelling ratio of hydrogels by continuous irradiation of green light $(\lambda=530 \mathrm{~nm})$ at $1.49 \mathrm{~mW} \mathrm{~cm}^{-2}$ with volume ratios of PU:DE of 1:10 (black), 1:20 (orange), and 1:30 (blue) ( $n=3$ technical replicates, mean \pm SD). C. Quantification of swelling ratio of hydrogels by continuous irradiation of green light at $1.49 \mathrm{~mW} \mathrm{~cm} \mathrm{~cm}^{-2}$ by DASA-esterase in absence of MR (blue), in presence of MR (orange), by DASA-esterase and PISA-urease in absence of MR (purple), in presence of MR (green), and DASA-esterase and PISA-urease with MR in darkness (black) $(n=3$ technical replicates, mean \pm SD). D. Photographs of the reversible hydrogel swelling states, in a 96-well microplate, followed in panel $\mathrm{E}$. The images were normalised to the distance corresponding to the bottom of the wells $(9 \mathrm{~mm})$. The scale bar corresponds to $1 \mathrm{~mm}$. E. Reversible swelling and de-swelling of hydrogels by alternating green light irradiation $(\lambda=530 \mathrm{~nm})$ at $1.49 \mathrm{~mW} \mathrm{~cm}^{-2}$ 
with darkness cycles. The second cycle required further addition of chemical fuel (ethyl acetate and urea) $(n=3$ technical replicates, mean $\pm \mathrm{SD})$.

\section{Supplementary Files}

This is a list of supplementary files associated with this preprint. Click to download.

- RifaieGrahametal.SI.docx

- ExtendedData.docx 